\title{
Thermohydraulic performance of microchannel heat sinks with triangular ribs on sidewalls - Part 2: average fluid flow and heat transfer characteristics
}

Lei Chai ${ }^{\mathrm{a},}{ }^{*}$, Liang Wang ${ }^{\mathrm{b}}$, Xin Baic

${ }^{a}$ RCUK National Centre for Sustainable Energy Use in Food Chain (CSEF), Brunel University London, Uxbridge, Middlesex UB8 3PH, UK

${ }^{\mathrm{b}}$ Institute of Engineering Thermophysics, Chinese Academy of Sciences, Beijing 100190, China

${ }^{c}$ Advanced Sustainable Manufacturing Technologies (ASTUTE 2020), College of Engineering, Swansea University, Swansea SA1 8EN, UK

\begin{abstract}
Triangular ribs mounted in the microchannel heat sink generally result in higher heat transfer coefficient, but are usually accompanied by higher pressure drop per unit length. In order to obtain some insight into the effect of geometry parameters of triangular ribs on laminar flow and heat transfer characteristics, three-dimensional conjugated heat transfer models taking account of the entrance effect, viscous heating and temperature-dependent thermophysical properties are conducted, and four non-dimensional variables related to the width, height, converging-diverging ratio and spacing of the triangular rib for both aligned and offset arrangements are designed. Effects of the geometry and arrangement of triangular ribs on thermohydraulic performance are examined by the variations of average friction factor and Nusselt number for Reynolds number (Re) ranging from 187 to 715 . The studied microchannels have the same width $\left(W_{\mathrm{c}}\right)$ of $0.1 \mathrm{~mm}$ and same depth $\left(H_{\mathrm{c}}\right)$ of $0.2 \mathrm{~mm}$ in the constant cross-section region. The geometric parameters of aligned or offset triangular ribs are ranged in $0.05-4 \mathrm{~mm}$ for width $\left(W_{\mathrm{r}}\right), 0.005-0.025$ $\mathrm{mm}$ for height $\left(H_{\mathrm{r}}\right), 0.2-5 \mathrm{~mm}$ for spacing $\left(S_{\mathrm{r}}\right)$ and 0-1 for the width ratio of converging region to a single rib

\footnotetext{
${ }^{*}$ Corresponding author. Tel.: +44 (0)1895 265834.

E-mail address: Lei.Chai@brunel.ac.uk (Lei Chai).
} 
$\left(W_{\text {con }} / W_{\mathrm{r}}\right)$. Based on the total 660 computational cases of the microchannel heat sinks with triangular ribs, the correlations of average friction factor and Nusselt number are proposed, respectively for aligned and offset arrangements. For the studied Reynolds number range and geometry parameters of flow passage, the microchannel heat sinks with aligned triangular ribs present 1.03-2.01 times higher of average Nusselt number and 1.06-9.09 times larger of average friction factor, and those with offset triangular ribs show 1.01-2.16 times higher of average Nusselt number and 1.04-7.43 times larger of average friction factor, compared with the reference straight microchannel heat sink. Proposed heat transfer and friction factor correlations show good agreements with the computational results for the microchannel heat sinks within the parameter ranges of $187 \leq R e \leq 715, \quad 0.25 \leq W_{\mathrm{r}} / W_{\mathrm{c}} \leq 4,0.05 \leq H_{\mathrm{r}} / W_{\mathrm{c}} \leq 0.25, \quad 0 \leq W_{\text {con }} / W_{\mathrm{c}} \leq 1$, and $2 \leq S_{\mathrm{r}} / W_{\mathrm{c}} \leq 50$.

Key words microchannel heat sinks; triangular ribs; pressure drop; heat transfer; parametric study

\section{Introduction}

Since the pioneering work by Tuckerman and Pease [1] in the early 1980s, the microchannel heat sink incorporating single-phase liquid flow has been successfully used for heat removal in a variety of devices, such as the cooling of electronic devices, automotive heat exchangers, laser process equipment and aerospace technology. The small size and its ability to dissipate heat generated by modern electronics make them the preferred choice for the electronic cooling systems. However, with the advancement in micro and nano electronics technology, the requirement of heat flux dissipation rate is reaching $1 \mathrm{~kW} / \mathrm{cm}^{2}$, which imposes limit on product design with traditional straight microchannel heat sink and requires advanced manufacturing technique and heat sink design with further higher heat removal capability $[2,3,4]$. In an attempt to improve overall thermal performance, different microchannel geometries with the potential to deliver high-heat flux 
rates have been proposed in recent years.

$\mathrm{Xu}$ et al. $[5,6]$ demonstrated the interrupted microchannel heat sink which consisted of a set of separated zones adjoining shortened parallel microchannels and transverse microchambers, Chai et al. [7, 8, 9] and Wong and Lee [10] introduced the staggered ribs into the transverse microchambers for further heat transfer augmentation and investigated the influence of rib geometry on heat transfer performance, Cao and Xu [11] suspended the consecutive conical-mesh inserts in channels to modulate flow and temperature fields. Promvonge et al. [12], Liu et al. [13], Ebrahimi et al. [14], Foong et al. [15] and Xie et al. [16] developed the microchannel heat sinks with passive microstructures inside, such as baffles, longitudinal vortex generators, internal longitudinal fins and internal bifurcations, and studied their fluid flow and heat transfer characteristics. Sui et al. [17, 18], Mohammed et al. [19] and Lin et al. [20] investigated the thermal performance of wavy microchannel heat sink with different geometry parameters, such as channel width, wall width, cross section aspect ratio and relative wavy amplitude, and Ghaedamini et al. [21] studied the developing forced convection in the converging-diverging microchannel heat sink. Chai et al. [22-29] and Beng and Japar [30] proposed several microchannel heat sink with different ribs and cavities on sidewalls and studied their thermohydraulic performance, and Xia et al. [31, 32, 33] and Ghani et al. [34, 35] introduced the ribs into the microchannel with cavities to further improve the heat transfer performance. Table 1 provides a brief summary of these studies, which depicts the flow condition, channel geometry and main findings.

Generally, the principles of enhanced heat transfer can be attributed to one or several of the following mechanisms, including the interruption of boundary layer formation, the enhanced convective fluid mixing, and the increased heat transfer surface area. However, the heat transfer augmentation methods usually lead to higher pressure drop penalty, and the application of such microchannel to electronics cooling imposes severe design constraints on the system design. For a given heat dissipation rate, the flow rate, pressure drop, fluid 
temperature rise, and fluid inlet to surface temperature difference requirements necessitate optimization of the channel geometry [36]. Further, as indicated in Table 1, for each type of microchannel heat sink, the geometry parameters of enhancement element in the form of rib, cavity, baffle, bifurcation and fin have a significant influence on the fluid low and heat transfer characteristics, which need more accurate data for the deep investigation of heat transfer process.

For the microchannel heat sink with aligned or offset ribs on sidewalls, Chai et al. [26] has conducted three-dimensional numerical models with five different shapes of offset ribs to examine the local and average friction factor, and further for a systematic and detailed analysis, Chai et al. [27, 28, 29] concentrated on the fan-shaped ribs and investigated the influence of rib geometry and arrangement on thermal and hydraulic characteristics of such microchannel heat sink. As a continuous study, we presently focus on the triangular ribs mounted in microchannels with either aligned or offset arrangements. The first part of this two-part study has supplied the basic fluid flow and heat transfer mechanism in such microchannel heat sink and identified the effects of the geometric and arrangement parameters on local fluid flow and heat transfer characteristics [37]. However, to design new microchannel heat sinks and evaluate their thermohydraulic performance, more accurate information on friction factor and heat transfer coefficients are required as a function of operation conditions and geometric parameters. Consequently, this second part emphasizes the effects of triangular rib geometry and arrangement on the average thermohydraulic performance in wide ranges of operation conditions and geometry and arrangement parameters. Altogether 660 computational cases have been conducted to investigate the effects of the geometric parameters on the thermohydraulic characteristics of the microchannel heat sinks with triangular ribs for Reynolds number ranging from 187 to 715 . As a result, the friction factor and Nusselt number correlations for microchannel heat sinks with triangular ribs are developed as a function of operation conditions and geometric parameters. 


\section{Computational method}

\subsection{Conservation equations}

A three-dimensional solid-fluid conjugate model is used to predict heat transfer performance for such microchannel heat sink with the following assumptions: developing flow, steady and laminar flow, varied fluid thermophysical properties and considering viscous dissipation. The continuity, momentum and energy equations for the problem can be written as

Continuity:

$\frac{\partial\left(\rho_{\mathrm{f}} u\right)}{\partial x}+\frac{\partial\left(\rho_{\mathrm{f}} v\right)}{\partial y}+\frac{\partial\left(\rho_{\mathrm{f}} w\right)}{\partial z}=0$

Momentum:

$$
\begin{aligned}
& \frac{\partial \rho_{\mathrm{f}} u u}{\partial x}+\frac{\partial \rho_{\mathrm{f}} u v}{\partial y}+\frac{\partial \rho_{\mathrm{f}} u w}{\partial z}=-\frac{\partial p}{\partial x}+\frac{\partial}{\partial x}\left(\mu_{\mathrm{f}} \frac{\partial u}{\partial x}\right)+\frac{\partial}{\partial y}\left(\mu_{\mathrm{f}} \frac{\partial u}{\partial y}\right)+\frac{\partial}{\partial z}\left(\mu_{\mathrm{f}} \frac{\partial u}{\partial z}\right) \\
& \frac{\partial \rho_{\mathrm{f}} v u}{\partial x}+\frac{\partial \rho_{\mathrm{f}} v v}{\partial y}+\frac{\partial \rho_{\mathrm{f}} v w}{\partial z}=-\frac{\partial p}{\partial y}+\frac{\partial}{\partial x}\left(\mu_{\mathrm{f}} \frac{\partial v}{\partial x}\right)+\frac{\partial}{\partial y}\left(\mu_{\mathrm{f}} \frac{\partial v}{\partial y}\right)+\frac{\partial}{\partial z}\left(\mu_{\mathrm{f}} \frac{\partial v}{\partial z}\right) \\
& \frac{\partial \rho_{\mathrm{f}} w u}{\partial x}+\frac{\partial \rho_{\mathrm{f}} w v}{\partial y}+\frac{\partial \rho_{\mathrm{f}} w w}{\partial z}=-\frac{\partial p}{\partial z}+\frac{\partial}{\partial x}\left(\mu_{\mathrm{f}} \frac{\partial w}{\partial x}\right)+\frac{\partial}{\partial y}\left(\mu_{\mathrm{f}} \frac{\partial w}{\partial y}\right)+\frac{\partial}{\partial z}\left(\mu_{\mathrm{f}} \frac{\partial w}{\partial z}\right)
\end{aligned}
$$

Energy equation for liquid:

$$
\begin{aligned}
& \frac{\partial \rho_{\mathrm{f}} u T}{\partial x}+\frac{\partial \rho_{\mathrm{f}} v T}{\partial y}+\frac{\partial \rho_{\mathrm{f}} w T}{\partial z}=\frac{\partial}{\partial x}\left(\frac{k_{\mathrm{f}}}{c_{\mathrm{pf}}} \frac{\partial T}{\partial x}\right)+\frac{\partial}{\partial y}\left(\frac{k_{\mathrm{f}}}{c_{\mathrm{pf}}} \frac{\partial T}{\partial y}\right)+\frac{\partial}{\partial z}\left(\frac{k_{\mathrm{f}}}{c_{\mathrm{pf}}} \frac{\partial T}{\partial z}\right)+\Phi \\
& \Phi=\mu_{\mathrm{f}}\left\{2\left[\left(\frac{\partial u}{\partial x}\right)^{2}+\left(\frac{\partial v}{\partial y}\right)^{2}+\left(\frac{\partial w}{\partial z}\right)^{2}\right]+\left(\frac{\partial u}{\partial y}+\frac{\partial v}{\partial x}\right)^{2}+\left(\frac{\partial u}{\partial z}+\frac{\partial w}{\partial x}\right)^{2}+\left(\frac{\partial v}{\partial z}+\frac{\partial w}{\partial y}\right)^{2}\right\}
\end{aligned}
$$

Energy equation for the solid

$$
\frac{\partial}{\partial x}\left(k_{\mathrm{s}} \frac{\partial T}{\partial x}\right)+\frac{\partial}{\partial y}\left(k_{\mathrm{s}} \frac{\partial T}{\partial y}\right)+\frac{\partial}{\partial z}\left(k_{\mathrm{s}} \frac{\partial T}{\partial z}\right)=0
$$

where $\rho$ is density, $\mu$ is dynamic viscosity, $c_{\mathrm{p}}$ is specific heat capacity and $k$ is thermal conductivity. Subscripts $\mathrm{f}$ and s refer to fluid and solid, respectively.

Water and silicon are respectively used as working fluid and heat sink substrate materials. The 
thermophysical properties of water including $\rho_{\mathrm{f}}, \mu_{\mathrm{f}}, c_{\mathrm{pf}}$ and $k_{\mathrm{f}}$ depend on temperatures as Incropera [38]. The thermal conductivity of silicon $k_{\mathrm{s}}$ is set $148 \mathrm{~W} \cdot \mathrm{m}^{-1} \mathrm{~K}^{-1}$ in the computation.

\subsection{Computational domain and boundary condition}

A unit cell containing a single microchannel and surrounding solid along with the base is chosen to perform the numerical analysis. Symmetry allows these results to be easily extended to the entire heat sink. Fig. 1a illustrates the unit cell, corresponding coordinate system, and key notations. The length $\left(L_{\mathrm{com}}\right)$, width $\left(W_{\mathrm{com}}\right)$ and height $\left(H_{\text {com }}\right)$ of the computational domain are $10 \mathrm{~mm}, 0.25 \mathrm{~mm}$ and $0.35 \mathrm{~mm}$, and the width $\left(W_{\mathrm{c}}\right)$ and height $\left(H_{\mathrm{c}}\right)$ of microchannel are $0.1 \mathrm{~mm}$ and $0.2 \mathrm{~mm}$, respectively. The triangular ribs are mounted on the two parallel sidewalls in tandem for both aligned and offset arrangements. The geometric parameters of triangular ribs are shown in Fig. $1 \mathrm{~b}$, including the width $\left(W_{\mathrm{r}}\right)$, the height $\left(H_{\mathrm{r}}\right)$, the spacing $\left(S_{\mathrm{r}}\right)$, and the contraction width ( $W_{\text {con }}$, which develop four non-dimensional variables, including the width ratio of the rib to microchannel $\left(W_{\mathrm{r}} / W_{\mathrm{c}}\right)$, ratio of the rib height to the microchannel width $\left(H_{\mathrm{r}} / W_{\mathrm{c}}\right)$, width ratio of converging region to the single rib $\left(W_{\text {con }} / W_{\mathrm{r}}\right)$, and ratio of the rib spacing to the microchannel width $\left(S_{\mathrm{r}} / W_{\mathrm{c}}\right)$. The studied ranges of these geometric parameters are 0.05-0.4 $\mathrm{mm}$ for $W_{\mathrm{r}}, 0.005-0.025 \mathrm{~mm}$ for $H_{\mathrm{r}}, 0.2-5 \mathrm{~mm}$ for $S_{\mathrm{r}}$. Also, a typical straight microchannel heat sink without ribs (MCHS) is selected for comparison.

For flow boundary conditions, a uniform velocity and a constant temperature are applied at the channel inlet $(x=0)$ for water and adiabatic for silicon. Five inlet flow velocities $u_{\text {in }}$ are selected to make sure the average velocity $(\bar{u})$ in the constant cross-section region is $1,2,3,4$ and $5 \mathrm{~m} \cdot \mathrm{s}^{-1}$ and the corresponding Reynolds number is $187,316,443,582$ and 715 , respectively, and the inlet temperature $T_{\text {in }}=293 \mathrm{~K}$ is specified. At the exit of the computational domain $(x=10 \mathrm{~mm})$, a pressure-outlet boundary condition $\left(p_{\text {out }}=0\right.$ for gauge pressure) is applied for water and adiabatic surface for the silicon. Symmetry is imposed on the left 
$(y=0.25 \mathrm{~mm})$ and right $(y=0)$ boundaries. At the bottom boundary $(z=0)$, a constant heat flux $\left(q=10^{6}\right.$ $\mathrm{W} \cdot \mathrm{m}^{-2}$ ) is imposed at the bottom wall. For other surfaces, adiabatic boundary condition is assumed.

\subsection{Solution methods}

The governing equations are solved using finite-volume-based commercial code, ANSYS FLUENT 12.0. The SIMPLEC algorithm is applied to solve the governing differential equations for the velocity, pressure and temperature fields in the control volume. The convergence criteria is that when the normalized residuals of all variables in momentum and energy equations are less than $10^{-5}$. The numerical code is verified in a number of ways to ensure the validity. For every microchannel, a grid independence test is checked using several different mesh sizes. Four different grid systems and the relative errors of fluid flow and heat transfer results are tabulated in Table 2 for the microchannel heat sink with offset triangular ribs of $W_{\mathrm{r}}=0.1 \mathrm{~mm}, H_{\mathrm{r}}=0.025$ $\mathrm{mm}, S_{\mathrm{r}}=0.4 \mathrm{~mm}$ and $W_{\text {con }}=0.07 \mathrm{~mm}$. The indicators of thermohydraulic performance are insensitive to further grid refinement (with deviations of $0.52 \%$ for friction factor, $0.85 \%$ for Nusselt number as $R e=443$ ) beyond a mesh of about 0.703 millions, which is used in the present study. In order to validate the accuracy and reliability of the numerical method in the present work, the numerical results are compared with the experimental results for straight microchannel heat sink conducted by Chai et al. [25]. The comparison between the computational and experimental results is demonstrated in Fig. 2, which shows good agreement of numerical results with the experimental data.

\section{Data acquisition}

Reynolds number:

$\operatorname{Re}=\frac{\rho_{\mathrm{f}} \bar{u} D_{\mathrm{h}}}{\mu_{\mathrm{f}}}$ 
where $\rho_{\mathrm{f}}$ is the volume average fluid density, $\bar{u}$ is the average flow velocity as mentioned above, $D_{\mathrm{h}}$ is the hydraulic diameter calculated based on the constant cross-section region, $\mu_{\mathrm{f}}$ is the mass average fluid dynamic viscosity. The $\rho_{\mathrm{f}}$ and $\mu_{\mathrm{f}}$ are defined as

$$
\begin{aligned}
& \rho_{\mathrm{f}}=\frac{\int \rho_{\mathrm{fi}} d V}{V} \\
& \mu_{\mathrm{f}}=\frac{\int \mu_{\mathrm{fi}} \rho_{\mathrm{f}, \mathrm{i}} d V}{\int \rho_{\mathrm{f}, \mathrm{i}} d V}
\end{aligned}
$$

Average heat transfer coefficient and Nusselt number:

$$
\begin{aligned}
& \bar{h}=\frac{q_{\mathrm{w}} L W}{A\left(\overline{T_{\mathrm{w}}}-\overline{T_{\mathrm{f}}}\right)} \\
& \overline{N u}=\frac{\bar{h} D_{\mathrm{h}}}{k_{\mathrm{f}}}
\end{aligned}
$$

where $q_{\mathrm{w}}$ represents heat flux at the silicon base, $A$ is the contact surface area of water and silicon based on the straight microchannel, $L$ and $W$ are respectively the length and width of computational domain, $k_{\mathrm{f}}$ is the mass average fluid thermal conductivity and defined as

$$
k_{\mathrm{f}}=\frac{\int k_{\mathrm{fi},} \rho_{\mathrm{fi}} d V}{\int \rho_{\mathrm{f}, \mathrm{i}} d V}
$$

$\overline{T_{\mathrm{w}}}$ and $\overline{T_{\mathrm{f}}}$ are the area-weighted temperature of the silicon base and the mass-average temperature of water in microchannels, respectively, defined as

$$
\begin{aligned}
& \overline{T_{\mathrm{w}}}=\frac{\int T_{\mathrm{w}, \mathrm{x}, \mathrm{y}} d y d x}{\int d y d x} \\
& \overline{T_{\mathrm{f}}}=\frac{\left.\int T_{\mathrm{f}, \mathrm{x}} \rho_{\mathrm{f}, \mathrm{x}}\right|^{\mathrm{r}} \cdot \stackrel{\mathrm{r}}{v} \cdot d A \mid d x}{\int \rho_{\mathrm{f}, \mathrm{i}, \mathrm{x}}\left|{ }^{\mathrm{r}} \cdot \stackrel{\mathrm{r}}{v} \cdot d x\right| d x}
\end{aligned}
$$

Average Fanning friction factor:

$$
\bar{f}=\frac{\left(p_{\text {in }}-p_{\text {out }}\right) D_{\mathrm{h}}}{2 \rho_{\mathrm{f}} L \bar{u}}
$$


where $p_{\text {in }}$ is the mass-weighted average pressure in the channel inlet and $p_{\text {out }}$ is the pressure in the channel outlet. The $p_{\text {in }}$ is defined as

$p_{\mathrm{in}}=\frac{\int p_{\mathrm{in}, \mathrm{i}} \rho_{\mathrm{f}, \mathrm{i}}|u \cdot d A|}{\int \rho_{\mathrm{f}, \mathrm{i}}|u \cdot d A|}$

\section{Results and discussion}

\subsection{Effect of rib width on average fluid flow and heat transfer characteristics}

Due to the significant importance of geometry of triangular ribs on fluid flow and heat transfer mechanism,

Fig. 3 firstly demonstrates the flow field and temperature distribution of computational fluid dynamics (CFD) results to indicate the benefit of the ribs. It can be seen that the triangular ribs can interrupt the development of thermal boundary layer due to the flow fluctuation near the walls, improve the convective fluid mixing due to the changed flow direction and flow passage, and increase heat transfer surface area due to the zigzag or wavy flow passage. Therefore, the microchannel with the triangular ribs has the potential to significantly improve the thermohydraulic performance. A detailed discussion of the contribution of the ribs to heat transfer enhancement is presented in the first part of this paper [37].

Figure 4 shows the variation of $\bar{f} R e$ and $\bar{f} / \bar{f}_{0}$ with $\operatorname{Re}$ and $W_{\mathrm{r}} / W_{\mathrm{c}}$, where $\bar{f}_{0}$ is the average Fanning friction factor of the reference MCHS. The $W_{\mathrm{r}}$ varies in the range of $0.05-0.4 \mathrm{~mm}$, and the other geometry parameters remain $H_{\mathrm{r}}=0.025 \mathrm{~mm}$ and $S_{\mathrm{r}}=0.4 \mathrm{~mm}$. As shown in Fig. $4 \mathrm{a}$, the $\bar{f} R e$ is obviously larger for the channels with triangular ribs, particularly for the aligned arrangement. The $\bar{f} R e$ increases with $R e$, and its increase rate slows down with increase of $W_{\mathrm{r}} / W_{\mathrm{c}}$. As shown in Fig. $4 \mathrm{~b}$, the $W_{\mathrm{r}} / W_{\mathrm{c}}$ has a significant influence on $\bar{f} / \bar{f}_{0}$, which is more obvious for the microchannel heat sink with aligned triangular ribs (MCHS-AFR) than those with offset triangular ribs (MCHS-OTR). Lower $W_{\mathrm{r}} / W_{\mathrm{c}}$ and higher $\operatorname{Re}$ lead to much higher $\bar{f} / \bar{f}_{0}$. The 
$\bar{f} / \bar{f}_{0}$ first declines and then climes slowly with increased $W_{\mathrm{r}} / W_{\mathrm{c}}$. With $W_{\mathrm{r}} / W_{\mathrm{c}}$ from 0.25 to 4 , the $\bar{f} / \bar{f}$ of MCHS-AFR varies from 3.21 to 2.64 then $3.42,4.13$ to 2.96 then $3.53,5.21$ to 3.22 then $3.66,6.34$ to 3.60 then $3.80,7.45$ to 3.93 then 3.96 respectively for $R e=187,316,443,582$ and 715 , while the $\bar{f} / \bar{f}_{0}$ of MCHS-OTR changes from 2.24 to 1.95 then $2.63,2.72$ to 2.13 then $2.71,3.26$ to 2.34 then $2.80,3.78$ to 2.48 then $2.85,4.23$ to 2.55 then 2.87 respectively for $R e=187,316,443,582$ and 715 . The $\bar{f} R e$ of reference MCHS is $13.27,14.26,14.85,15.45$ and 16.04 respectively as $R e=187,316,443,582$ and 715.

Figure 5 presents the effect of $R e$ and $W_{\mathrm{r}} / W_{\mathrm{c}}$ on $\overline{N u}$ and $\overline{N u} / \overline{N u}_{0}$, where $\overline{N u_{0}}$ is the average Nusselt number of the reference MCHS. As shown in Fig. 5a, the triangular ribs result in significantly larger $\overline{N u}$, the $\overline{N u}$ obviously increases with $R e$, and different $W_{\mathrm{r}} / W_{\mathrm{c}}$ leads to different increase rate of $\overline{N u}$. As shown in Fig. 5b, for a specific $R e$, the $\overline{N u} / \overline{N u}_{0}$ fluctuates with increase of $W_{\mathrm{r}} / W_{\mathrm{c}}$, which is different from the variation of $\bar{f} / \bar{f}_{0}$, suggesting sophisticated heat transfer characteristic. Different $W_{\mathrm{r}} / W_{\mathrm{c}}$ and varied Re lead to different fluid developing quality, different mixing level of cold and hot fluid, and uncertain scope of recirculation zone, thus different contributions to heat transfer enhancement. It should be point that, as $W_{\mathrm{r}} / W_{\mathrm{c}}=4$, the straight constant-cross-sectional area disappears, the MCHS-ATR reduces to the converging-diverging microchannel and the MCHS-OTR evolves to the zigzag or wave microchannel. As shown in Fig. 5a, the channels with $W_{\mathrm{r}} / W_{\mathrm{c}}=4$ do not show preferable heat transfer performance, indicating that the MCHS-ATR and MCHS-OTR with some optimal triangular rib geometry can perform better, respectively, than the converging-diverging microchannel and the zigzag or wave microchannel. With the increase of $W_{\mathrm{r}} / W_{\mathrm{c}}$ from 0.25 to 4 , the $\overline{N u} / \overline{N u}$ o for MCHS-ATR varies in the ranges of 1.40-1.73, 1.49-1.93, 1.52-1.95, 1.60-1.90 and 1.64-1.90 respectively for $R e=187,316,443,582$ and 715, and the $\overline{N u} / \overline{N u}_{0}$ for MCHS-OTR changes in the ranges of 1.41-1.74, $1.54-1.95,1.53-1.97,1.47-1.93$ and 1.44-1.88 respectively for $R e=187,316,443,582$ and 715 . The baseline $\overline{N u}$ of MCHS is 4.96, 5.58, 6.09, 6.52 and 6.91 respectively as $R e=187,316,443,582$ and 715 . 


\subsection{Effect of rib height on average fluid flow and heat transfer characteristics}

Figures 6 and 7 show the variation of $\bar{f} R e$ and $\bar{f} / \bar{f}_{0}$ with $R e$ and $H_{\mathrm{r}} / W_{\mathrm{c}}$. The $H_{\mathrm{r}}$ changes in the range $0.005-0.025 \mathrm{~mm}$ and the other geometry parameters keep $W_{\mathrm{r}}=0.1$ or $0.2 \mathrm{~mm}, W_{\text {con }}=0.07$ or $0.14 \mathrm{~mm}$, and $S_{\mathrm{r}}$ $=0.4 \mathrm{~mm}$. As shown in Figs. $6 \mathrm{a}$ and $7 \mathrm{a}$, the increase of $H_{\mathrm{r}} / W_{\mathrm{c}}$ results in large increase of $\bar{f} R e$, especially for the MCHS-ATR. The $\bar{f} R e$ of channels with $H_{\mathrm{r}} / W_{\mathrm{c}}=0.05$ is almost similar to that of MCHS, indicating that the lower triangular ribs immerse under the hydraulic boundary layer and exert little influence on the fluid flow. The $\bar{f} R e$ of channels with $H_{\mathrm{r}} / W_{\mathrm{c}}=0.1$ is a little more and becomes obviously larger for the channels with further larger $H_{\mathrm{r}} / W_{\mathrm{c}}$ than that of MCHS, suggesting the ribs effectively interrupted the hydraulic boundary layer and caused much pressure drop penalty. Correspondingly, as $H_{\mathrm{r}} / W_{\mathrm{c}}=0.05$, the $\bar{f} / \bar{f}_{0}$ is closed not only for the different rib arrangements but also for the different $R e ;$ as $H_{\mathrm{r}} / W_{\mathrm{c}}>0.1$, the increased $H_{\mathrm{r}} / W_{\mathrm{c}}$ leads to increased $\bar{f} / \bar{f}_{0}$ and faster increase rate of $\bar{f} / \bar{f}_{0}$ with $R e$. A larger $H_{\mathrm{r}} / W_{\mathrm{c}}$ also causes more difference of $\bar{f} / \bar{f}_{0}$ between MCHS-ATR and MCHS-OTR. Additionally, different $W_{\mathrm{r}} / W_{\mathrm{c}}$ leads to different increase rate of $\bar{f} R e$ and $\bar{f} / \bar{f}_{0}$ with $H_{\mathrm{r}} / W_{\mathrm{c}}$. For MCHS-ATR with $H_{\mathrm{r}} / W_{\mathrm{c}}$ from 0.05 to 0.25 , the $\bar{f} / \bar{f}_{0}$ increases from 1.10 to $2.73,1.06$ to $3.35,1.07$ to $4.04,1.07$ to 4.69 and 1.08 to 5.30 for $W_{\mathrm{r}} / W_{\mathrm{c}}=1,1.13$ to 2.75 , 1.09 to $2.95,1.09$ to $3.30,1.09$ to 3.66 and 1.10 to 4.05 for $W_{\mathrm{r}} / W_{\mathrm{c}}=2$, respectively as $R e=187,316,443,582$ and 715. For MCHS-OTR with $H_{\mathrm{r}} / W_{\mathrm{c}}$ from 0.05 to 0.25 , the $\bar{f} / \bar{f}_{0}$ rises from 1.09 to $2.03,1.06$ to $2.35,1.06$ to $2.69,1.06$ to 2.99 and 1.07 to 3.26 for $W_{\mathrm{r}} / W_{\mathrm{c}}=1,1.12$ to $2.04,1.08$ to $2.21,1.08$ to $2.38,1.09$ to 2.51 and 1.09 to 2.65 for $W_{\mathrm{r}} / W_{\mathrm{c}}=2$, respectively as $R e=187,316,443,582$ and 715 .

Figures 8 and 9 demonstrate the change of $\overline{N u}$ and $\overline{N u} / \overline{N u}_{0}$ with $R e$ and $H_{\mathrm{r}} / W_{\mathrm{c}}$. The increased $H_{\mathrm{r}} / W_{\mathrm{c}}$ leads to significant increase of $\overline{N u}$ but variable tendency of $\overline{N u} / \overline{N u}$. The $\overline{N u}$ of channels with $H_{\mathrm{r}} / W_{\mathrm{c}}=$ 0.05 is almost similar to that of MCHS, indicating that the lower triangular ribs cannot interrupted the thermal 
boundary layer. As $H_{\mathrm{r}} / W_{\mathrm{c}}>0.1$, the $\overline{N u}$ becomes obviously higher than that of MCHS, proving the triangular rib as an effective heat transfer enhancement method. For $W_{\mathrm{r}} / W_{\mathrm{c}}=1$, the MCHS-OTR shows closed $\overline{N u}$ as $H_{\mathrm{r}} / W_{\mathrm{c}}<0.2$ and obviously larger $\overline{N u}$ as $H_{\mathrm{r}} / W_{\mathrm{c}}>0.2$ in contrast to the MCHS-ATR. For $W_{\mathrm{r}} / W_{\mathrm{c}}=2$, the MCHS-ATR performs better than the MCHS-OTR as $R e>443$ and $H_{\mathrm{r}} / W_{\mathrm{c}}>0.15$. For MCHS-ATR with $H_{\mathrm{r}} / W_{\mathrm{c}}$ from 0.05 to 0.25 , the $\overline{N u} / \overline{N u}_{0}$ varies from 1.05 to $1.58,1.06$ to $1.76,1.06$ to $1.79,1.06$ to 1.78 and 1.06 to 1.77 then 1.74 for $W_{\mathrm{r}} / W_{\mathrm{c}}=1,1.03$ to $1.46,1.03$ to $1.50,1.04$ to $1.61,1.04$ to 1.72 then 1.70 and 1.05 to 1.81 then 1.80 for $W_{\mathrm{r}} / W_{\mathrm{c}}=2$, respectively as $R e=187,316,443,582$ and 715 . For MCHS-OTR with $H_{\mathrm{r}} / W_{\mathrm{c}}$ from 0.05 to 0.25 , the $\overline{N u} / \overline{N u}_{0}$ climes from 1.05 to $1.64,1.06$ to $1.90,1.05$ to $1.95,1.05$ to 1.91 and 1.05 to 1.86 for $W_{\mathrm{r}} / W_{\mathrm{c}}=1,1.03$ to $1.54,1.04$ to $1.76,1.04$ to $1.79,1.05$ to 1.73 and 1.05 to 1.70 for $W_{\mathrm{r}} / W_{\mathrm{c}}=2$, respectively as $R e=187,316,443,582$ and 715 .

\subsection{Effect of rib's converging-diverging ratio on average fluid flow and heat transfer characteristics}

Figures 10 and 11 show the variation of $\bar{f} R e$ and $\bar{f} / \bar{f}_{0}$ with $R e$ and $W_{\text {con }} / W_{\mathrm{r}}$. For a specific $R e$, the $\bar{f} R e$ firstly decreases and then increases with increase of $W_{\text {con }} / W_{\mathrm{r}}$ for both aligned and offset arrangements. And the $W_{\text {con }} / W_{\mathrm{r}}$ corresponding to the lowest $\bar{f} R e$ moves with changed rib width: $W_{\text {con }} / W_{\mathrm{r}}=0.7$ as $W_{\mathrm{r}} / W_{\mathrm{c}}=1$ and $W_{\text {con }} / W_{\mathrm{r}}=0.5$ as $W_{\mathrm{r}} / W_{\mathrm{c}}=2$. As shown in Figs. $10 \mathrm{~b}$ and $11 \mathrm{~b}$, the larger Re and the aligned arrangement respectively lead to higher $\bar{f} / \bar{f}_{0}$. As $W_{\mathrm{r}} / W_{\mathrm{c}}=1$, the $\bar{f} / \bar{f}_{0}$ declines quickly as $W_{\mathrm{con}} / W_{\mathrm{r}}<0.3$ and then slowly as $W_{\text {con }} / W_{\mathrm{r}}>0.3$, while as $W_{\mathrm{r}} / W_{\mathrm{c}}=2$, the $\bar{f} / \bar{f}_{0}$ declines as $W_{\text {con }} / W_{\mathrm{r}}<0.3$ and remains similar as $0.3<$ $W_{\text {con }} / W_{\mathrm{r}}<0.7$ and then increases as $W_{\text {con }} / W_{\mathrm{r}}>0.7$. For MCHS-ATR with $W_{\text {con }} / W_{\mathrm{r}}$ from 0 to 1 , the $\bar{f} / \bar{f}$ 。 changes in the range of 2.59 to $2.90,3.53$ to $4.24,4.03$ to $6.07,5.03$ to 7.66 and 5.30 to 9.10 for $W_{\mathrm{r}} / W_{\mathrm{c}}=1$, 2.60 to $3.21,2.79$ to $3.74,3.06$ to $4.36,3.38$ to 5.23 and 3.69 to 6.09 for $W_{\mathrm{r}} / W_{\mathrm{c}}=2$, respectively as $R e=187$, 316, 443, 582 and 715. For MCHS-OTR with $W_{\text {con }} / W_{\mathrm{r}}$ from 0 to 1 , the $\bar{f} / \bar{f}_{0}$ varies ranging from 1.95 to 
2.10, 2.27 to $2.43,2.63$ to $2.97,2.89$ to 3.57 and 3.11 to 4.17 for $W_{\mathrm{r}} / W_{\mathrm{c}}=1,1.94$ to $2.26,2.05$ to $2.49,2.17$ to $2.73,2.30$ to 3.12 and 2.38 to 3.85 for $W_{\mathrm{r}} / W_{\mathrm{c}}=2$, respectively as $R e=187,316,443,582$ and 715 .

Figures 12 and 13 present the effects of $R e$ and $W_{\text {con }} / W_{\mathrm{r}}$ on $\overline{N u}$ and $\overline{N u} / \overline{N u}_{0}$. For MCHS-ATR, the increase rate of $\overline{N u}$ with $R e$ becomes lower with increase of $W_{\text {con }} / W_{\mathrm{r}}$, while for MCHS-OTR, the tendency is not clear. And there is no very large difference of $\overline{N u}$ between MCHS-ATR and MCHS-OTR. For $W_{\mathrm{r}} / W_{\mathrm{c}}=1$ as shown in Fig. 12b, the $\overline{N u} / \overline{N u}_{0}$ generally increases with increase of $W_{\text {con }} / W_{\mathrm{r}}$ as $R e=187$, but does not show clear tendency as $R e>316$ for both MCHS-ATR and MCHS-OTR. For $W_{\mathrm{r}} / W_{\mathrm{c}}=2$ as shown in Fig. 13b, the $\overline{N u} / \overline{N u}_{0}$ generally increases with increase of $W_{\text {con }} / W_{\mathrm{r}}$ as $R e=187$ and 316, and decreases a little and then increases slowly as $R e=582$ and 715, and the $\overline{N u} / \overline{N u}_{0}$ of MCHS-ATR drops as $R e>443$ and $W_{\text {con }} / W_{\mathrm{r}}>0.8$, while that of MCHS-OTR is not clear. For MCHS-ATR with $W_{\text {con }} / W_{\mathrm{r}}$ from 0 to 1 , the $\overline{N u} / \overline{N u}_{0}$ varies in the range of 1.25 to $1.72,1.55$ to $1.94,1.75$ to $1.95,1.73$ to 1.90 and 1.68 to 1.89 for $W_{\mathrm{r}} / W_{\mathrm{c}}=1,1.13$ to $1.75,1.26$ to $1.89,1.46$ to $1.89,1.60$ to 1.89 and 1.63 to 1.87 for $W_{\mathrm{r}} / W_{\mathrm{c}}=2$, respectively as $R e=187,316,443,582$ and 715. For MCHS-OTR with $W_{\text {con }} / W_{\mathrm{r}}$ from 0 to 1 , the $\overline{N u} / \overline{N u}_{0}$ varies in the range of 1.25 to $1.75,1.60$ to 1.97 , 1.71 to $2.00,1.72$ to 1.96 and 1.69 to 1.91 for $W_{\mathrm{r}} / W_{\mathrm{c}}=1,1.14$ to $1.76,1.30$ to $1.96,1.50$ to $1.95,1.53$ to 1.92 and 1.58 to 1.87 for $W_{\mathrm{r}} / W_{\mathrm{c}}=2$, respectively as $R e=187,316,443,582$ and 715 .

\subsection{Effect of rib spacing on average fluid flow and heat transfer characteristics}

Figures 14 and 15 demonstrate the variation of $\bar{f} R e$ and $\bar{f} / \bar{f}_{0}$ with $R e$ and $S_{\mathrm{r}} / W_{\mathrm{c}}$. The decreased $S_{\mathrm{r}} / W_{\mathrm{c}}$ result in dramatic increase of $\bar{f} R e$ and $\bar{f} / \bar{f}_{0}$ for the channels with triangular ribs. As shown in Table 3 , the decrease of $S_{\mathrm{r}} / W_{\mathrm{c}}$ indicates the more triangular ribs. As a result, the shorted constant cross section region is kept at higher hydrodynamic developing level, which causes larger pressure drop penalty. The $\bar{f} / \bar{f}_{0}$ of MCHS-ATR is always larger than MCHS-OTR, and its increase rate with decreased $S_{\mathrm{r}} / W_{\mathrm{c}}$ for MCHS-ATR is 
firstly larger and then lower than MCHS-OTR. With the decrease of $S_{\mathrm{r}} / W_{\mathrm{c}}$ from 50 to 2 , the $\bar{f} / \bar{f}_{0}$ of MCHS-ATR increases from 1.18 to $4.23,1.21$ to $5.37,1.27$ to $6.51,1.34$ to 7.54 and 1.40 to 8.57 for $W_{\mathrm{r}} / W_{\mathrm{c}}=1$, from 1.18 to $4.26,1.16$ to $4.69,1.18$ to $5.26,1.22$ to 5.85 and 1.25 to 6.40 for $W_{\mathrm{r}} / W_{\mathrm{c}}=2$, respectively for $R e=$ 187, 316, 443, 582 and 715; the $\bar{f} / \bar{f}_{0}$ of MCHS-OTR increases from 1.10 to 3.52, 1.08 to 4.44, 1.11 to 5.44, 1.14 to 6.49 and 1.17 to 7.43 for $W_{\mathrm{r}} / W_{\mathrm{c}}=1$, from 1.10 to $3.71,1.07$ to $4.03,1.08$ to $4.39,1.08$ to 4.75 and 1.09 to 5.14 for $W_{\mathrm{r}} / W_{\mathrm{c}}=2$, respectively for $R e=187,316,443,582$ and 715 .

Figures 16 and 17 show the effects of $R e$ and $S_{\mathrm{r}} / W_{\mathrm{c}}$ on $\overline{N u}$ and $\overline{N u} / \overline{N u}{ }_{0}$. For $W_{\mathrm{r}} / W_{\mathrm{c}}=1$, there is no obvious difference of $\overline{N u}$ between MCHS-ATR and MCHS-OTR as $S_{\mathrm{r}} / W_{\mathrm{c}}>10$ and the MCHS-OTR shows higher $\overline{N u}$ as $S_{\mathrm{r}} / W_{\mathrm{c}}<10$. For $W_{\mathrm{r}} / W_{\mathrm{c}}=2$, the MCHS-ATR shows higher $\overline{N u}$ than MCHS-ATR only as $R e>$ 443 and $S_{\mathrm{r}} / W_{\mathrm{c}}>10$. The decreased $S_{\mathrm{r}} / W_{\mathrm{c}}$ usually leads to increased $\overline{N u} / \overline{N u}_{0}$, and the increase tendency for MCHS-ATR keeps well. Additionally, as $W_{\mathrm{r}} / W_{\mathrm{c}}=2$, the $\overline{N u} / \overline{N u}_{0}$ of MCHS-OTR with $S_{\mathrm{r}} / W_{\mathrm{c}}=2.5$ is significantly larger than that with $S_{\mathrm{r}} / W_{\mathrm{c}}=2$, indicating that again the MCHS-OTR with optimal geometry parameter can perform better heat transfer than zigzag or wavy channel (The channel with $W_{\mathrm{r}} / W_{\mathrm{c}}=2$ and $S_{\mathrm{r}} / W_{\mathrm{c}}$ $=2$ reduces zigzag or wavy channel). With the decrease of $S_{\mathrm{r}} / W_{\mathrm{c}}$ from 50 to 2 , the $\overline{N u} / \overline{N u}$ of MCHS-ATR increases from 1.06 to $1.86,1.11$ to $2.00,1.14$ to $1.98,1.17$ to 1.93 and 1.19 to 1.91 for $W_{\mathrm{r}} / W_{\mathrm{c}}=1$, from 1.05 to $1.69,1.07$ to $1.72,1.09$ to $1.75,1.12$ to 1.79 and 1.15 to 1.80 for $W_{\mathrm{r}} / W_{\mathrm{c}}=2$, respectively for $R e=187,316$, 443, 582 and 715; the $\overline{N u} / \overline{N u}_{0}$ of MCHS-OTR increases from 1.05 to 1.91 then 1.90, 1.09 to 2.16 then 2.05, 1.13 to 2.16 then $2.03,1.16$ to 2.09 then 1.97 and 1.18 to 2.02 then 1.90 for $W_{\mathrm{r}} / W_{\mathrm{c}}=1$, from 1.02 to 1.75 then $1.71,1.05$ to 2.00 then $1.71,1.06$ to 1.98 then $1.68,1.07$ to 1.91 then 1.74 and 1.07 to 1.87 then 1.74 for $W_{\mathrm{r}} / W_{\mathrm{c}}$ $=2$, respectively for $R e=187,316,443,582$ and 715 .

\subsection{Pressure drop and heat transfer correlations}


Based on the total of 660 computational cases, the correlations of pressure drop, as a function of $R e, W_{\mathrm{r}} / W_{\mathrm{c}}$, $H_{\mathrm{r}} / W_{\mathrm{c}}, W_{\mathrm{con}} / W_{\mathrm{r}}$ and $S_{\mathrm{r}} / W_{\mathrm{c}}$, are deduced by least squares as follows:

MCHS-ATR: $\bar{f} R e=22.14171 R e^{0.4702}\left(W_{\mathrm{r}} / W_{\mathrm{c}}\right)^{-0.1608}\left(H_{\mathrm{r}} / W_{\mathrm{c}}\right)^{0.9238}\left(W_{\mathrm{con}} / W_{\mathrm{r}}\right)^{0.0623}\left(S_{\mathrm{r}} / W_{\mathrm{c}}\right)^{-0.4445}$

MCHS-OTR: $\bar{f} R e=17.9312 R e^{0.3608}\left(W_{\mathrm{r}} / W_{\mathrm{c}}\right)^{-0.0922}\left(H_{\mathrm{r}} / W_{\mathrm{c}}\right)^{0.6462}\left(W_{\mathrm{con}} / W_{\mathrm{r}}\right)^{-0.01}\left(S_{\mathrm{r}} / W_{\mathrm{c}}\right)^{-0.3611}$

for $187 \leq R e \leq 715, \quad 0.25 \leq W_{\mathrm{r}} / W_{\mathrm{c}} \leq 4, \quad 0.05 \leq H_{\mathrm{r}} / W_{\mathrm{c}} \leq 0.25, \quad 0 \leq W_{\text {con }} / W_{\mathrm{c}} \leq 1$, and $2 \leq S_{\mathrm{r}} / W_{\mathrm{c}} \leq 50$.

The correlations of heat transfer, as a function of $\operatorname{Re}, \operatorname{Pr}, W_{\mathrm{r}} / W_{\mathrm{c}}, H_{\mathrm{r}} / W_{\mathrm{c}}, W_{\mathrm{con}} / W_{\mathrm{r}}$ and $S_{\mathrm{r}} / W_{\mathrm{c}}$, are deduced by least squares method as follows:

MCHS-ATR: $\overline{N u}=1.8701 \operatorname{Re}^{0.3134} \operatorname{Pr}^{0.3}\left(W_{\mathrm{r}} / W_{\mathrm{c}}\right)^{-0.0649}\left(H_{\mathrm{r}} / W_{\mathrm{c}}\right)^{0.3365}\left(W_{\mathrm{con}} / W_{\mathrm{r}}\right)^{0.0595}\left(S_{\mathrm{r}} / W_{\mathrm{c}}\right)^{-0.1568}$

MCHS-OTR: $\overline{N u}=2.4868 R e^{0.2838} \operatorname{Pr}^{0.3}\left(W_{\mathrm{r}} / W_{\mathrm{c}}\right)^{-0.0911}\left(H_{\mathrm{r}} / W_{\mathrm{c}}\right)^{0.3608}\left(W_{\mathrm{con}} / W_{\mathrm{r}}\right)^{0.0728}\left(S_{\mathrm{r}} / W_{\mathrm{c}}\right)^{-0.1811}$

for $187 \leq R e \leq 715, \quad 0.25 \leq W_{\mathrm{r}} / W_{\mathrm{c}} \leq 4, \quad 0.05 \leq H_{\mathrm{r}} / W_{\mathrm{c}} \leq 0.25, \quad 0 \leq W_{\text {con }} / W_{\mathrm{c}} \leq 1$, and $2 \leq S_{\mathrm{r}} / W_{\mathrm{c}} \leq 50$.

Figure 18 compares predictions of these correlations with the present computational results. The predictive accuracy of the correlations is measured by mean absolute error, which is defined as

MAE $=\frac{1}{N} \sum_{i=1}^{N} \frac{\left|\overline{N u}_{\text {pred }}-\overline{N u}_{\text {cfd }}\right|}{\overline{N u}_{\text {cfd }}} \times 100 \%$

It can be found that most data points are shown falling within $\pm 20 \%$ error bands for $\bar{f} R e$, with MAE $=13.2 \%$ for MCHS-ATR and MAE $=11.8 \%$ for MCHS-OTR, and within $\pm 10 \%$ error bands for $\overline{N u}$, with MAE $=$ $5.1 \%$ for MCHS-ATR and MAE $=5.1 \%$ for MCHS-OTR.

\section{Conclusions}

In this paper, the triangular ribs with different geometry are designed based on the rectangular straight microchannel. The effects of the width, height, converging-diverging ratio and spacing of the triangular rib for both aligned and offset arrangements on average laminar fluid flow and heat transfer characteristics are 
studied. New pressure drop and heat transfer correlations are proposed. Based on the foregoing discussions, the following conclusions are concluded:

(1) Triangular ribs mounted on the two parallel sidewalls of microchannel can significantly improve the heat transfer performance, but also accompany by a higher pressure drop penalty. The triangular ribs' geometry and arrangement show a variety of influence on the average thermohydraulic performance, both from one configuration to another and form lower Reynolds number to higher.

(2) Increased Reynolds number, increased rib height and declined rib spacing usually result in both larger pressure drop and heat transfer coefficient. The offset triangular ribs can lead to similar average heat transfer but much lower pressure drop than the aligned ones with the same geometry. The MCHS-ATR and MCHS-OTR with optimal triangular rib geometry can present higher Nusselt number but lower friction factor, respectively, than the converging-diverging microchannel and the zigzag or wave microchannel.

(3) For the studied Reynolds number ranging from 187 to 715 , the microchannel heat sinks with different aligned triangular ribs present 1.03-2.01 times higher of heat transfer and 1.06-9.09 times larger of pressure drop, and those with different offset triangular ribs show 1.01-2.16 times higher of heat transfer and 1.04-7.43 times larger of pressure drop, in contrast to the reference straight microchannel.

(4) New fluid flow and heat transfer correlations for the microchannel heat sinks with triangular ribs on sidewalls show good agreements with the computational results within the parameter ranges of $187 \leq R e \leq 715, \quad 0.25 \leq W_{\mathrm{r}} / W_{\mathrm{c}} \leq 4, \quad 0.05 \leq H_{\mathrm{r}} / W_{\mathrm{c}} \leq 0.25, \quad 0 \leq W_{\text {con }} / W_{\mathrm{c}} \leq 1$, and $2 \leq S_{\mathrm{r}} / W_{\mathrm{c}} \leq 50$. The mean absolute error is $13.2 \%$ of $\bar{f} R e$ and $5.1 \%$ of $\overline{N u}$ for MCHS-AFR and $11.8 \%$ of $\bar{f} R e$ and $5.1 \%$ of $\overline{N u}$ for MCHS-OFR. 
(5) According to the present investigations, several recommendations are suggested for future works: The laminar fluid flow and heat transfer mechanism in microchannel heat sinks with triangular ribs can be further extended to other flow systems in microscale; The proposed correlations should be further validated with experimental data in future when they are available; Cost-based objective functions with reasonable weightings assigned to heat transfer and pressure drop should be investigated for some specific applications of heat sink design; Combine passive or active techniques in mini/microchannel heat sinks can be used for further heat transfer augmentation, such as nanofluid and nanoencapsulated phase change slurry employed as working fluid. 


\section{Acknowledgements}

The work was supported by the Engineering and Physical Sciences Research Council (EPSRC) of the UK through research grant (RRR1025R33470) and the Youth Innovation Promotion Association of CAS (2016131). 


\section{References}

[1] D.B. Tuckerman, R.F.W. Pease, High-performance heat sinking for VLSI, IEEE Electron Device Letters 2 (1981) 126-129.

[2] A.M. Adham, N. Mohd-Ghazali, R. Ahmad, Thermal and hydrodynamic analysis of microchannel heat sinks: A review, Renewable and Sustainable Energy Reviews 21 (2013) 614-622.

[3] L. Chai, G.D. Xia, J.Z. Qi, Experimental and numerical study of flow and heat transfer in trapezoidal microchannels, Heat Transfer Engineering 33 (2012) 972-981.

[4] S.G. Kandlikar, S. Colin, Y. Peles, S. Garimella, R.F. Pease, J.J. Brandner, D.B. Tuckerman, Heat transfer in microchannels-2012 status and research needs, Journal of Heat Transfer 135 (2013) 091001.

[5] J.L. Xu, Y.H. Gan, D.C. Zhang, Microscale heat transfer enhancement using thermal boundary layer redeveloping concept, International Journal of Heat and Mass Transfer 48 (2005) 1662-1674.

[6] J.L Xu, Y.X Song, W. Zhang, Numerical simulations of interrupted and conventional microchannel heat sinks, International Journal of Heat and Mass Transfer 51 (2008) 5906-5917.

[7] L. Chai, G.D. Xia, M. Zhou, J. Li, J. Qi, Optimum thermal design of interrupted microchannel heat sink with rectangular ribs in the transverse microchambers, Applied Thermal Engineering 51 (2013) $880-889$.

[8] L. Chai, G.D. Xia, H.S. Wang, Laminar flow and heat transfer characteristics of interrupted microchannel heat sink with ribs in the transverse microchambers, International Journal of Thermal Sciences $110(2016) 1-11$.

[9] L. Chai, L. Wang, Thermohydraulic performance of interrupted microchannel heat sinks with different rib geometries in transverse microchambers, International Journal of Thermal Sciences 127 (2018) 
201-212.

[10] K.C. Wong, J.H. Lee, Investigation of thermal performance of microchannel heat sink with triangular ribs in the transverse microchambers, International Communications in Heat and Mass Transfer 65 (2015) 103-110.

[11] Z. Cao, J.L. Xu. Modulated heat transfer tube with short conical-mesh inserts: A linking from microflow to macroflow, International Journal of Heat and Mass Transfer 89 (2015) 291-307.

[12] P. Promvonge, S. Sripattanapipat, S. Kwankaomeng, Laminar periodic flow and heat transfer in square channel with $45^{\circ}$ inline baffles on two opposite walls, International Journal of Thermal Sciences 49 (2010) 963-975.

[13] C. Liu, J. Teng, J.C. Chu, Experimental investigations on liquid flow and heat transfer in rectangular microchannel with longitudinal vortex generators, International Journal of Heat and Mass Transfer 54 (2011) 3069-3080.

[14] A. Ebrahimi, R. Ehsan Roohi, K. Saeid, Numerical study of liquid flow and heat transfer in rectangular microchannel with longitudinal vortex generators, Applied Thermal Engineering 78 (2015) 576-583.

[15] A.J. Foong, N. Ramesh, T.T. Chandratilleke, Laminar convective heat transfer in a microchannel with internal longitudinal fins, International Journal of Thermal Sciences 48 (2009) 1908-1913.

[16] G. Xie, H Shen, C.C. Wang, Parametric study on thermal performance of microchannel heat sinks with internal vertical Y-shaped bifurcations, International Journal of Heat and Mass Transfer 90 (2015) $948-958$.

[17] Y. Sui, C.J. Teo, P.S. Lee, Fluid flow and heat transfer in wavy microchannels, International Journal of Heat and Mass Transfer 53 (2010) 2760-2772.

[18] Y. Sui, P.S. Lee, C.J. Teo, An experimental study of flow friction and heat transfer in wavy 
microchannels with rectangular cross section, International Journal of Thermal Sciences 50 (2011) $2473-2482$.

[19] H.A. Mohammed, P. Gunnasegaran, N.H. Shuaib, Numerical simulation of heat transfer enhancement in wavy microchannel heat sink, International Communications in Heat and Mass Transfer 38 (2011) $63-68$.

[20] L. Lin, J. Zhao, G Lu, X.D. Wang, W.M. Yan, Heat transfer enhancement in microchannel heat sink by wavy channel with changing wavelength/amplitude, International Journal of Thermal Sciences 118 (2017) 423-434.

[21] H. Ghaedamini, P.S. Lee, C.J. Teo, Developing forced convection in converging-diverging microchannels, International Journal of Heat and Mass Transfer 65 (2013) 491-499.

[22] L. Chai, G.D. Xia, M.Z. Zhou, Numerical simulation of fluid flow and heat transfer in a microchannel heat sink with offset fan-shaped reentrant cavities in sidewall, International Communications in Heat and Mass Transfer 38 (2011) 577-584.

[23] G.D. Xia, L. Chai, M.Z. Zhou, Effects of structural parameters on fluid flow and heat transfer in a microchannel with aligned fan-shaped reentrant cavities, International Journal of Thermal Sciences 50 (2011) 411-419.

[24] G.D. Xia, L. Chai, H.Y. Wang, Optimum thermal design of microchannel heat sink with triangular reentrant cavities, Applied Thermal Engineering 31 (2011) 1208-1219.

[25] L. Chai, G.D. Xia, L. Wang, M.Z. Zhou, Z.Z. Cui, Heat transfer enhancement in microchannel heat sinks with periodic expansion-constriction cross-sections, International Journal of Heat and Mass Transfer 62 (2013) 741-751.

[26] L. Chai, G.D. Xia, H.S. Wang, Numerical study of laminar flow and heat transfer in microchannel heat 
sink with offset ribs on sidewalls, Applied Thermal Engineering 92 (2016) 32-41

[27] L. Chai, G.D. Xia, H.S. Wang, Parametric study on thermal and hydraulic characteristics of laminar flow in microchannel heat sink with fan-shaped ribs on sidewalls-Part 1: Heat transfer, International Journal of Heat and Mass Transfer 97 (2016) 1069-1080.

[28] L. Chai, G.D. Xia, H.S. Wang, Parametric study on thermal and hydraulic characteristics of laminar flow in microchannel heat sink with fan-shaped ribs on sidewalls-Part 2: Pressure drop, International Journal of Heat and Mass Transfer 97 (2016) 1081-1090.

[29] L. Chai, G.D. Xia, H.S. Wang, Parametric study on thermal and hydraulic characteristics of laminar flow in microchannel heat sink with fan-shaped ribs on sidewalls-Part 3: Performance evaluation, International Journal of Heat and Mass Transfer 97 (2016) 1091-1101

[30] S.W. Beng, W.M.A.A Japar, Numerical analysis of heat and fluid flow in microchannel heat sink with triangular cavities, Journal of Advanced Research in Fluid Mechanics and Thermal Sciences 34 (2017) $1-8$.

[31] G.D. Xia, Y.L. Zhai, Z.Z. Cui, Numerical investigation of thermal enhancement in a micro heat sink with fan-shaped reentrant cavities and internal ribs, Applied Thermal Engineering 58 (2013) 52-60.

[32] Y.L. Zhai, G.D. Xia, X.F. Liu, Heat transfer in the microchannels with fan-shaped reentrant cavities and different ribs based on field synergy principle and entropy generation analysis, International journal of heat and mass transfer 68 (2014) 224-233.

[33] Y.F. Li, G.D. Xia, D.D. Ma, Characteristics of laminar flow and heat transfer in microchannel heat sink with triangular cavities and rectangular ribs, International Journal of Heat and Mass Transfer 98 (2016) $17-28$.

[34] I.A. Ghani, N. Kamaruzaman, N.A.C. Sidik, Heat transfer augmentation in a microchannel heat sink 
with sinusoidal cavities and rectangular ribs, International Journal of Heat and Mass Transfer 108 (2017) 1969-1981.

[35] I.A. Ghani, N.A.C. Sidik, R. Mamat, Heat transfer enhancement in microchannel heat sink using hybrid technique of ribs and secondary channels, International Journal of Heat and Mass Transfer 114 (2017) $640-655$.

[36] S. Kandlikar, S Garimella, D. Li, S. Colin, M.R. King, Heat transfer and fluid flow in minichannels and microchannels, Elsevier, 2005

[37] L. Chai, L. Wang, X. Bai, Thermohydraulic performance of microchannel heat sinks with triangular ribs on sidewalls - Part 1: Local fluid flow and heat transfer characteristics, International Journal of Heat and Mass Transfer 127 (2018) 1124-1137.

[38] F. Incropera, Liquid Cooling of Electronic Devices by Single-Phase Convection, Wiley, 1999. 


\begin{tabular}{|c|c|}
\hline \multicolumn{2}{|c|}{ Nomenclature } \\
\hline$A$ & area, $\mathrm{m}^{2}$ \\
\hline$c_{p}$ & specific heat, $\mathrm{J} \cdot \mathrm{kg}^{-1} \mathrm{~K}^{-1}$ \\
\hline$D_{\mathrm{h}}$ & hydraulic diameter, $\mathrm{m}$ \\
\hline $\bar{f}$ & average friction factor \\
\hline$h$ & heat transfer coefficient, $\mathrm{W} \cdot \mathrm{m}^{-2} \mathrm{~K}^{-1}$ \\
\hline $\bar{h}$ & average heat transfer coefficient, $\mathrm{W} \cdot \mathrm{m}^{-2} \cdot \mathrm{K}^{-1}$ \\
\hline$H$ & height, $\mathrm{m}$ \\
\hline$k$ & thermal conductivity, $\mathrm{W} \cdot \mathrm{m}^{-1} \cdot \mathrm{K}^{-1}$ \\
\hline$L$ & length, m \\
\hline$N u$ & Nusselt number \\
\hline$\overline{N u}$ & average Nusselt number \\
\hline$p$ & pressure, $\mathrm{Pa}$ \\
\hline$q$ & heat flux, $\mathrm{W} \cdot \mathrm{m}^{-2}$ \\
\hline $\operatorname{Re}$ & Reynolds number \\
\hline$S$ & spacing, $\mathrm{m}$ \\
\hline$T$ & temperature, $\mathrm{K}$ \\
\hline $\bar{T}$ & average temperature, $\mathrm{K}$ \\
\hline$u$ & velocity, $\mathrm{m} \cdot \mathrm{s}^{-1}$ \\
\hline $\bar{u}$ & average velocity, $\mathrm{m} \cdot \mathrm{s}^{-1}$ \\
\hline
\end{tabular}




\begin{tabular}{|c|c|}
\hline$W$ & width, m \\
\hline$x, y, z$ & three coordinates shown in Fig. 1a, m \\
\hline \multicolumn{2}{|c|}{ Greek letters } \\
\hline$\rho$ & density, $\mathrm{kg} \cdot \mathrm{m}^{-3}$ \\
\hline$\mu$ & dynamic viscosity, $\mathrm{Pa} \cdot \mathrm{s}$ \\
\hline \multicolumn{2}{|c|}{ Subscripts } \\
\hline $\mathrm{c}$ & channel \\
\hline com & computational domain \\
\hline con & contraction \\
\hline $\exp$ & experimental \\
\hline in & inlet \\
\hline f & fluid \\
\hline out & outlet \\
\hline $\mathrm{r}$ & rib \\
\hline $\mathrm{s}$ & silicon \\
\hline $\mathrm{w}$ & heat sink base \\
\hline \multicolumn{2}{|c|}{ Abbreviations } \\
\hline ATR & aligned triangular ribs \\
\hline CFD & computational fluid dynamics \\
\hline MCHS & microchannel heat sink \\
\hline OTR & offset triangular ribs \\
\hline
\end{tabular}




\section{Figure captions}

Table 1 Representative studies of heat transfer enhancement for microchannel heat sink.

Table 2 Check of grid independence (MCHS-OTR with $W_{\mathrm{r}}=0.1 \mathrm{~mm}, H_{\mathrm{r}}=0.025 \mathrm{~mm}, S_{\mathrm{r}}=0.4 \mathrm{~mm}$ and $W_{\text {con }}=$ $0.07 \mathrm{~mm}, \operatorname{Re}=443)$.

Table 3 Number of fan-shaped ribs on each sidewall and the corresponding value of $S_{\mathrm{r}}$.

Fig. 1 Microchannel heat sinks with triangular ribs on sidewalls. (a) Computational domain. (b) Geometry parameters and arrangement of triangular ribs.

Fig. 2 Verification of numerical model.

Fig. 3 CFD plots of velocity and temperature distributions.

Fig. 4 Effects of rib width on average hydraulic characteristic $\left(H_{\mathrm{r}} / W_{\mathrm{c}}=0.25, W_{\text {con }} / W_{\mathrm{r}}=0.7\right.$ and $\left.S_{\mathrm{r}} / W_{\mathrm{c}}=4\right)$.

(a) $\bar{f} R e$ versus $R e$. (b) $\bar{f} / \bar{f}_{0}$ versus $W_{\mathrm{r}} / W_{\mathrm{c}}$.

Fig. 5 Effects of rib width on average heat transfer characteristic $\left(H_{\mathrm{r}} / W_{\mathrm{c}}=0.25, W_{\text {con }} / W_{\mathrm{r}}=0.7\right.$ and $\left.S_{\mathrm{r}} / W_{\mathrm{c}}=4\right)$.

(a) $\overline{N u}$ versus $R e$. (b) $\overline{N u} / \overline{N u}_{0}$ versus $W_{\mathrm{r}} / W_{\mathrm{c}}$.

Fig. 6 Effects of rib height on average hydraulic characteristic $\left(W_{\mathrm{r}} / W_{\mathrm{c}}=1, W_{\text {con }} / W_{\mathrm{r}}=0.7\right.$ and $\left.S_{\mathrm{r}} / W_{\mathrm{c}}=4\right)$.

(a) $\bar{f} R e$ versus $R e$. (b) $\bar{f} / \bar{f}_{0}$ versus $H_{\mathrm{r}} / W_{\mathrm{c}}$.

Fig. 7 Effects of rib height on average hydraulic characteristic $\left(W_{\mathrm{r}} / W_{\mathrm{c}}=2, W_{\mathrm{con}} / W_{\mathrm{r}}=0.7\right.$ and $\left.S_{\mathrm{r}} / W_{\mathrm{c}}=4\right)$.

(a) $\bar{f} R e$ versus $R e$. (b) $\bar{f} / \bar{f}_{0}$ versus $H_{\mathrm{r}} / W_{\mathrm{c}}$.

Fig. 8 Effects of rib height on average heat transfer characteristic $\left(W_{\mathrm{r}} / W_{\mathrm{c}}=1, W_{\text {con }} / W_{\mathrm{r}}=0.7\right.$ and $\left.S_{\mathrm{r}} / W_{\mathrm{c}}=4\right)$.

(a) $\overline{N u}$ versus $R e$. (b) $\overline{N u} / \overline{N u}_{0}$ versus $H_{\mathrm{r}} / W_{\mathrm{c}}$.

Fig. 9 Effects of rib height on average heat transfer characteristic $\left(W_{\mathrm{r}} / W_{\mathrm{c}}=2, W_{\text {con }} / W_{\mathrm{r}}=0.7\right.$ and $\left.S_{\mathrm{r}} / W_{\mathrm{c}}=4\right)$.

(a) $\overline{N u}$ versus $R e$. (b) $\overline{N u} / \overline{N u}_{0}$ versus $H_{\mathrm{r}} / W_{\mathrm{c}}$. 
Fig. 10 Effects of rib's converging-diverging ratio on average hydraulic characteristic $\left(W_{\mathrm{r}} / W_{\mathrm{c}}=1, H_{\mathrm{r}} / W_{\mathrm{c}}=\right.$ 0.25 and $\left.S_{\mathrm{r}} / W_{\mathrm{c}}=4\right)$. (a) $\bar{f} R e$ versus $R e .(\mathrm{b}) \bar{f} / \bar{f}_{0}$ versus $W_{\text {con }} / W_{\mathrm{r}}$.

Fig. 11 Effects of rib's converging-diverging ratio on average hydraulic characteristic $\left(W_{\mathrm{r}} / W_{\mathrm{c}}=2, H_{\mathrm{r}} / W_{\mathrm{c}}=\right.$ 0.25 and $\left.S_{\mathrm{r}} / W_{\mathrm{c}}=4\right)$. (a) $\bar{f} R e$ versus $R e .(\mathrm{b}) \bar{f} / \bar{f}_{0}$ versus $W_{\text {con }} / W_{\mathrm{r}}$.

Fig. 12 Effects of rib's converging-diverging ratio on average heat transfer characteristic $\left(W_{\mathrm{r}} / W_{\mathrm{c}}=1, H_{\mathrm{r}} / W_{\mathrm{c}}=\right.$ 0.25 and $\left.S_{\mathrm{r}} / W_{\mathrm{c}}=4\right)$. (a) $\overline{N u}$ versus $R e$. (b) $\overline{N u} / \overline{N u}_{0}$ versus $W_{\text {con }} / W_{\mathrm{r}}$.

Fig. 13 Effects of rib's converging-diverging ratio on average heat transfer characteristic $\left(W_{\mathrm{r}} / W_{\mathrm{c}}=2, H_{\mathrm{r}} / W_{\mathrm{c}}=\right.$ 0.25 and $\left.S_{\mathrm{r}} / W_{\mathrm{c}}=4\right)$. (a) $\overline{N u}$ versus $R e$. (b) $\overline{N u} / \overline{N u}_{0}$ versus $W_{\text {con }} / W_{\mathrm{r}}$.

Fig. 14 Effects of rib spacing on average hydraulic characteristic $\left(W_{\mathrm{r}} / W_{\mathrm{c}}=1, H_{\mathrm{r}} / W_{\mathrm{c}}=0.25\right.$ and $\left.W_{\text {con }} / W_{\mathrm{r}}=0.7\right)$. (a) $\bar{f} R e$ versus $R e$. (b) $\bar{f} / \bar{f}_{0}$ versus $S_{\mathrm{r}} / W_{\mathrm{c}}$.

Fig. 15 Effects of rib spacing on average hydraulic characteristic $\left(W_{\mathrm{r}} / W_{\mathrm{c}}=2, H_{\mathrm{r}} / W_{\mathrm{c}}=0.25\right.$ and $\left.W_{\text {con }} / W_{\mathrm{r}}=0.7\right)$.

(a) $\bar{f} R e$ versus $R e$. (b) $\bar{f} / \bar{f}_{0}$ versus $S_{\mathrm{r}} / W_{\mathrm{c}}$.

Fig. 16 Effects of rib spacing on average heat transfer characteristic $\left(W_{\mathrm{r}} / W_{\mathrm{c}}=1, H_{\mathrm{r}} / W_{\mathrm{c}}=0.25\right.$ and $W_{\text {con }} / W_{\mathrm{r}}=$ 0.7). (a) $\overline{N u}$ versus $R e$. (b) $\overline{N u} / \overline{N u_{0}}$ versus $S_{\mathrm{r}} / W_{\mathrm{c}}$.

Fig. 17 Effects of rib spacing on average heat transfer characteristic $\left(W_{\mathrm{r}} / W_{\mathrm{c}}=2, H_{\mathrm{r}} / W_{\mathrm{c}}=0.25\right.$ and $W_{\text {con }} / W_{\mathrm{r}}=$ 0.7). (a) $\overline{N u}$ versus $R e$. (b) $\overline{N u} / \overline{N u}_{0}$ versus $S_{\mathrm{r}} / W_{\mathrm{c}}$.

Fig. 18 Comparison of predictions of proposed correlations with the present CFD simulated data. (a) $\bar{f} R e$. (b) $\overline{N u}$. 
Table 1 Representative studies of heat transfer enhancement for microchannel heat sink.

\begin{tabular}{|c|c|c|c|}
\hline References & Reynold range & Channel geometry & Main findings \\
\hline Xu et al. $[5,6]$ & $100-1100$ & $\begin{array}{l}\text { Interrupted microchannel with several } \\
\text { transverse microchambers }\end{array}$ & $\begin{array}{l}\text { Interrupted microchannel can significant reduce the pressure drop while greatly } \\
\text { enhance heat transfer due to the repeated thermal developing flow, and may lead } \\
\text { to the earlier transition from laminar flow to turbulent flow. }\end{array}$ \\
\hline Chai et al. [7] & $187-715$ & $\begin{array}{l}\text { Interrupted microchannel with } \\
\text { rectangular ribs in transverse } \\
\text { microchambers }\end{array}$ & $\begin{array}{l}\text { Configuration of the rectangular ribs has significant influence on fluid flow and } \\
\text { heat transfer characteristics, and the interrupted microchannel with ribs is } \\
\text { suitable to the operating condition of } R e<600 \text {, while for } R e>600 \text {, the } \\
\text { interrupted microchannel without ribs is considered better. }\end{array}$ \\
\hline Chai et al. $[8,9]$ & $187-715$ & $\begin{array}{l}\text { Interrupted microchannel with five } \\
\text { different rib configurations in } \\
\text { transverse microchambers }\end{array}$ & $\begin{array}{l}\text { Nusselt number is increased by } 24-57 \% \text { for the interrupted microchannel heat } \\
\text { sinks with ribs, while the friction factor is increased by } 3-70 \% \text {. The microchannel } \\
\text { with ellipsoidal ribs shows the best heat transfer performance, with maximum } \\
1.39 \text { of performance evaluation criteria. }\end{array}$ \\
\hline Wong and Lee $[10]$ & $300-700$ & $\begin{array}{l}\text { Interrupted microchannel with } \\
\text { triangular ribs in transverse } \\
\text { microchambers }\end{array}$ & $\begin{array}{l}\text { Geometry of the triangular ribs have important influence on fluid flow and heat } \\
\text { transfer characteristics. Nusselt number ratio reveals an optimum enhancement of } \\
56 \% \text { relative to non-interrupted microchannel heat sink. }\end{array}$ \\
\hline Cao and $\mathrm{Xu}[11]$ & $100-1500$ & $\begin{array}{l}\text { Channels with short conical-mesh } \\
\text { inserts }\end{array}$ & $\begin{array}{l}\text { Nusselt numbers are } 1.4-4.1 \text { times of that in a bare channel, performance } \\
\text { evaluation criteria is up to } 2.2 \text {, demonstrating excellent heat transfer } \\
\text { enhancement at low flow rate pumping cost. }\end{array}$ \\
\hline Promvonge et al. [12] & $100-1000$ & Microchannel with $45^{\circ}$ inline & The $45^{\circ}$ inline baffles lead to drastic increase in heat transfer rate over the \\
\hline
\end{tabular}


Liu et al. [13]

$170-1200$

(1)

Ebrahimi et al. [14]

$100-1000$

Foong et al. [15]

$1100-1330$

Xie et al. [16]

Sui et al. [17]

Sui et al. [18]

$300-800$

Mohammed et al. [19] 100-1000
Microchannel with longitudinal vortex generators

Microchannel with longitudinal vortex generators

Microchannel with
longitudinal fins

longitudinal fins

Microchannel heat sinks with internal Internal Y-shaped bifurcations lead to much better thermal performance than that vertical Y-shaped bifurcations

Wavy microchannel heat sink

Wavy microchannel heat sink

Wavy microchannel heat sink

number and friction factor.

Heat transfer performance is improved by $9-90 \%$, while encountering larger pressure drop 34-169\%. Laminar-to-turbulent transition of rectangular microchannel occurs earlier than that for the smooth rectangular microchannel.

A $2-25 \%$ increase in the Nusselt number, while the friction factor increased by $4-30 \%$. Higher overall efficiency is attainable at higher volume flow rates.

internal Internal fins in a microchannel have the potential to provide heat transfer augmentation. For a given microchannel, there is an optimum fin height that provides the best possible heat transfer and pressure drop characteristics.

of the traditional rectangular microchannel, and a larger arm angle results in a better thermal performance.

Relative waviness can be increased along the flow direction and result in an increase in heat transfer performance.

Heat transfer performance can be much better than that of straight microchannels, and pressure drop penalty can be much smaller than the heat transfer enhancement.

Heat transfer performance can be much better than the straight microchannels and the pressure drop penalty can be much smaller than the heat transfer enhancement achievement. Both friction factor and wall shear stress are 
Wavy microchannel heat sink

Converging-diverging

heat sink

Microchannel heat sink with offse fan-shaped reentrant cavities

sidewall

Microchannel with triangular reentrant cavities

Microchannel with periodic expansion-constriction cross-sections
Heat sink with decreased wavelength or increased amplitude along the flow direction yields a lower thermal resistance and a smaller temperature difference on the bottom wall. The increased absolute value of the wavelength difference or the amplitude difference between two adjacent wavy units can further enhance heat transfer.

Heat transfer can increase drastically albeit with a higher pressure drop penalty. The superiority of converging-diverging design shows itself at higher $R e$ for which higher performance of up to $20 \%$ is observed.

The heat transfer enhancement strongly depends on the $R e$, and a larger $R e$ leads to a significant increase of Nusselt number. Fluid flow and heat transfer much depend on the structural parameters of the microchannel. Optimal parameters of fan-shaped reentrant cavities are found for such microchannel heat sink.

Fluid flow and heat transfer much depend on the structural parameters of the microchannel. Increased $R e$ can greatly enhance the heat transfer but with a dramatically increased pressure drop penalty. Optimal parameters of triangular reentrant cavities are obtained for such microchannel heat sink.

Heat transfer can be significantly enhanced with the averaged Nusselt number increased up to 1.8 times higher. Pressure drop is lower for lower Re, increases rapidly and becomes obviously higher at larger $R e$, compared with the straight microchannel. 


\begin{tabular}{|c|c|c|c|}
\hline Chai et al. [26] & $190-838$ & $\begin{array}{l}\text { Microchannel with five different } \\
\text { configuration offset ribs on sidewalls }\end{array}$ & $\begin{array}{l}\text { Offset ribs result in significant heat transfer enhancement but higher pressure } \\
\text { drop, which are respectively } 1.42-1.95 \text { and } 1.93-4.57 \text { times higher than straight } \\
\text { microchannel, leading to performance evaluation criteria of } 1.02-1.48 \text {. }\end{array}$ \\
\hline Chai et al. [27, 28, 29] & $187-715$ & $\begin{array}{l}\text { Microchannel heat sink with } \\
\text { fan-shaped ribs on sidewalls }\end{array}$ & $\begin{array}{l}\text { For the studied Re range and geometric parameters and in contrast to the straight } \\
\text { microchannel, there are a } 6-101 \% \text { increase in average Nusselt number, } 1.1-8.28 \\
\text { times larger in average friction factor for the microchannel heat sink with aligned } \\
\text { fan-shaped ribs, while a } 4-103 \% \text { increase in average Nusselt number, and } \\
1.22-6.27 \text { times higher in average friction factor for the microchannel heat sink } \\
\text { with offset fan-shaped ribs. The best microchannel heat sink shows a } 32 \% \\
\text { decrease in entropy generation rate and } 1.33 \text { in performance evaluation criteria, } \\
\text { compared with the straight microchannel. }\end{array}$ \\
\hline Beng and Japar [30] & $200-1200$ & $\begin{array}{l}\text { Microchannel heat sink with triangular } \\
\text { cavities }\end{array}$ & $\begin{array}{l}\text { Triangular cavities channel with the highest volume nanofluids }(15 \%) \text { can lead to } \\
\text { maximum Nusselt number up to } 29.5 \text {. }\end{array}$ \\
\hline Xia et al. $[31,32]$ & $150-600$ & $\begin{array}{l}\text { Microchannel heat sink with } \\
\text { fan-shaped reentrant cavities and } \\
\text { internal ribs }\end{array}$ & $\begin{array}{l}\text { Combined effect of cavity and rib has better performance of heat transfer, and the } \\
\text { effect of relative rib height is stronger than the individual effect of the } \\
\text { arrangement or the size of reentrant cavity when } R e>300 \text {. Heat transfer } \\
\text { enhancement can be attributed to the good synergy between velocity vector and } \\
\text { temperature gradient. }\end{array}$ \\
\hline Xia et al. [33] & $173-635$ & $\begin{array}{l}\text { Microchannel heat sink with triangular } \\
\text { cavities and rectangular ribs }\end{array}$ & $\begin{array}{l}\text { Triangular cavities and rectangular ribs result in significant heat transfer } \\
\text { enhancement. Fluid flow and heat transfer much depend on the structural } \\
\text { parameters of the microchannel, the best microchannel shows } 1.619 \text { in }\end{array}$ \\
\hline
\end{tabular}


performance evaluation criteria.

Ghani et al. [34] 100-800

Ghani et al. [35]
Microchannel heat sink with sinusoidal

cavities and rectangular ribs

Using of hybrid techniques between heat transfer augmentation methods such as

ribs and cavities can be significantly enhanced overall performance in microchannel heat sink rather than using individual technique. Fluid flow and heat transfer much depend on the structural parameters of the microchannel, the best microchannel shows 1.85 in performance evaluation criteria.

Microchannel heat sink using hybrid

technique of ribs and secondary

channels
Utilizing the secondary channels with ribs can contribute in reducing the pressure drop and enhancing the heat transfer. The influence of parameters, including relative secondary channel width relative rib width and the angle of secondary channel, on thermohydraulic performance are investigated. 
Table 2 Check of grid independence (MCHS-OTR with $W_{\mathrm{r}}=0.1 \mathrm{~mm}, H_{\mathrm{r}}=0.025 \mathrm{~mm}, S_{\mathrm{r}}=0.4 \mathrm{~mm}$ and $W_{\text {con }}=$ $0.07 \mathrm{~mm}, \operatorname{Re}=443)$.

\begin{tabular}{lllll}
\hline Number of cells (million) & $\overline{N u}$ & Relative Error (\%) & $\bar{f} R e$ & Relative Error (\%) \\
\hline 0.086 & 10.33 & 13.6 & 35.51 & 11.8 \\
0.293 & 11.15 & 6.78 & 37.58 & 6.62 \\
0.467 & 11.61 & 2.91 & 39.15 & 2.73 \\
0.703 & 11.86 & 0.85 & 40.04 & 0.52 \\
1.123 & 11.96 & 0 & 40.25 & 0 \\
\hline
\end{tabular}


Table 3 Number of fan-shaped ribs on each sidewall and the corresponding value of $S_{\text {r }}$.

\begin{tabular}{cccccccccccc}
\hline Number & 2 & 4 & 5 & 8 & 10 & 16 & 20 & 25 & 32 & 40 & 50 \\
\hline$S_{\mathrm{r}} / W_{\mathrm{c}}$ & 50 & 25 & 20 & 12.5 & 10 & 6.25 & 5 & 4 & 3.125 & 2.5 & 2 \\
\hline
\end{tabular}


Fig. 1

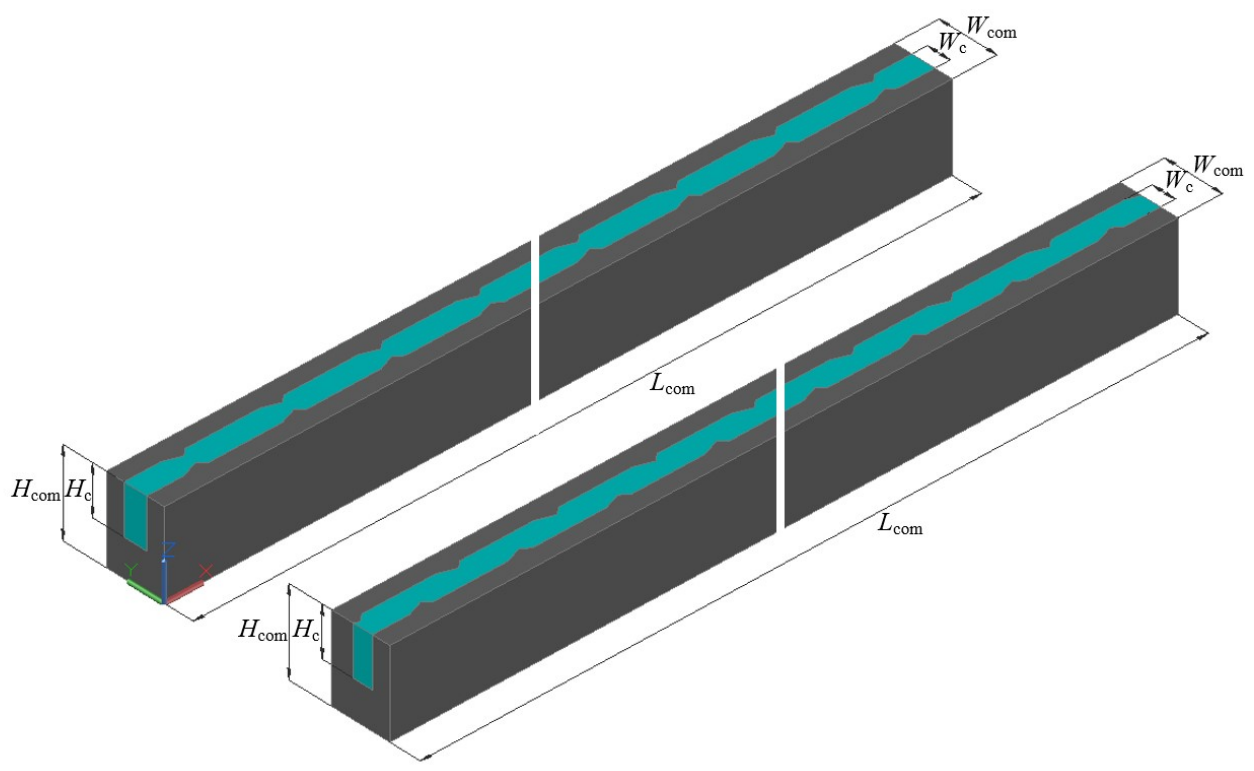

(a)
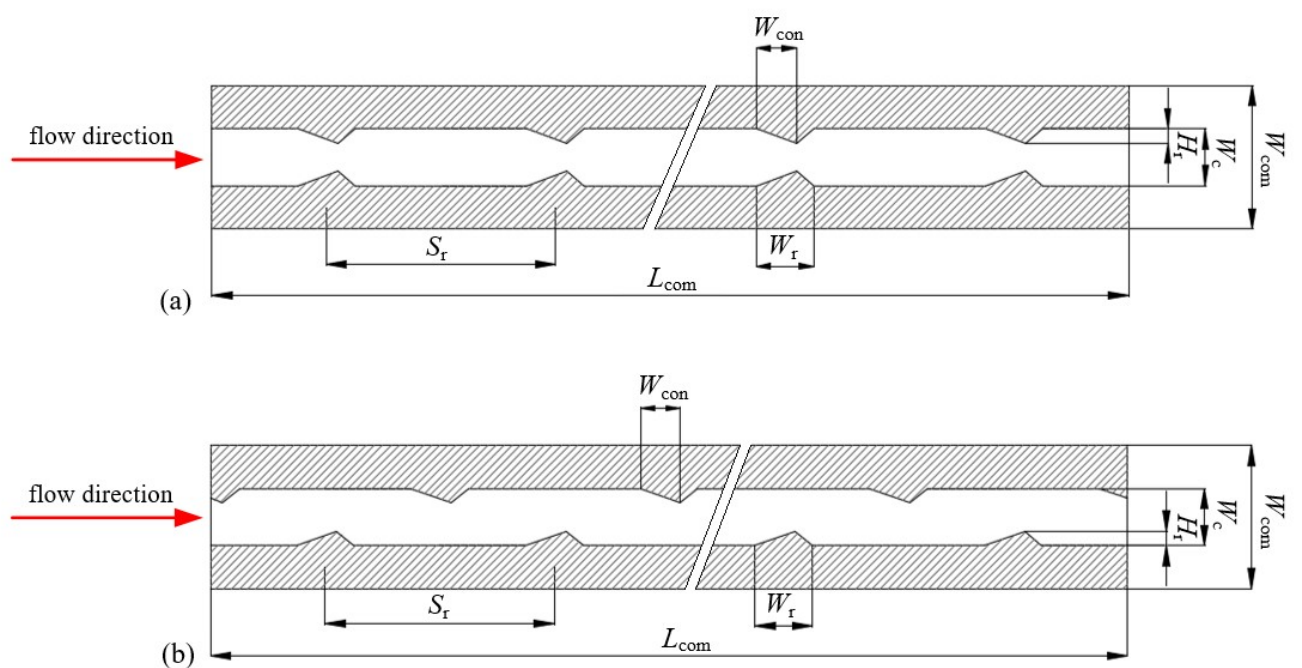

(b) 
Fig. 2

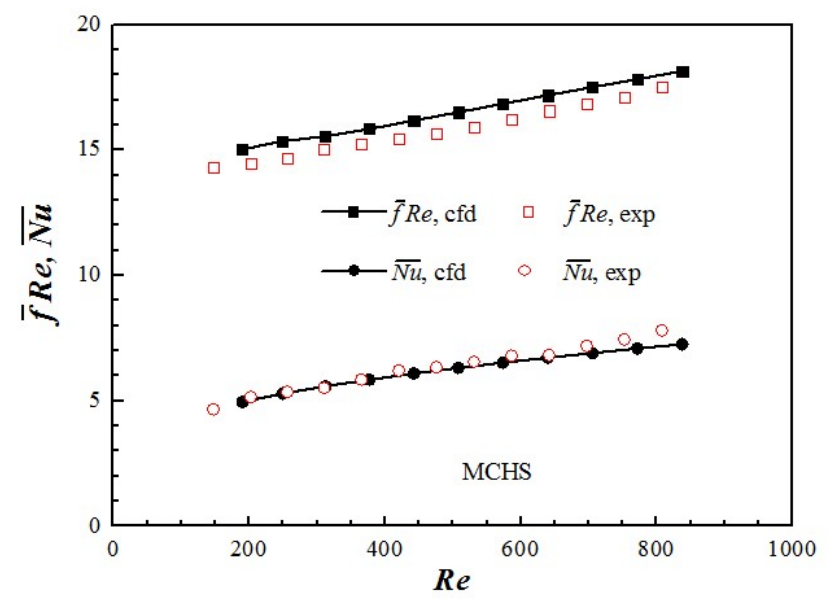


Fig. 3

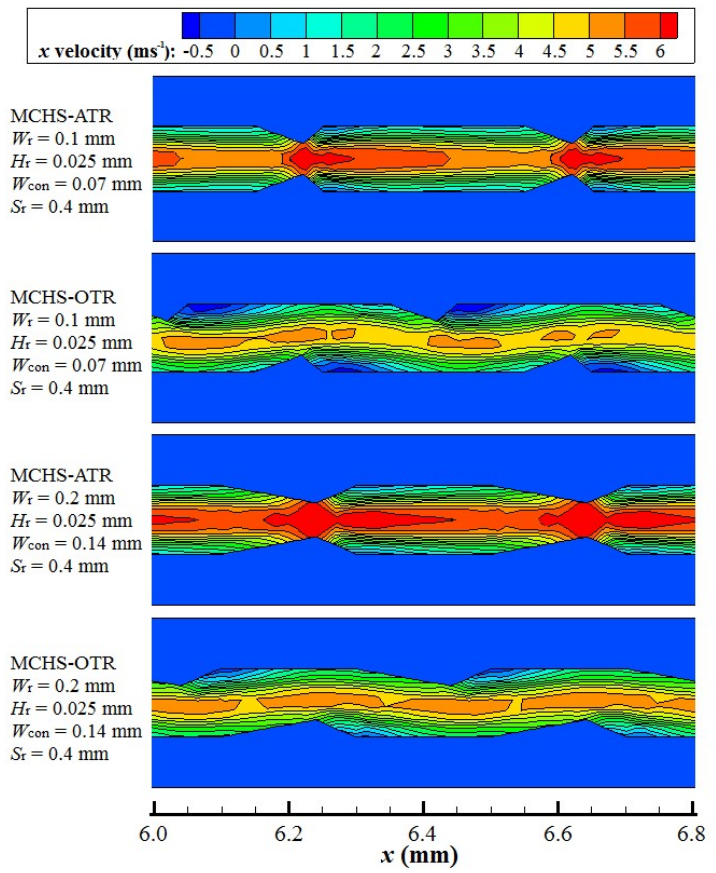

(a)
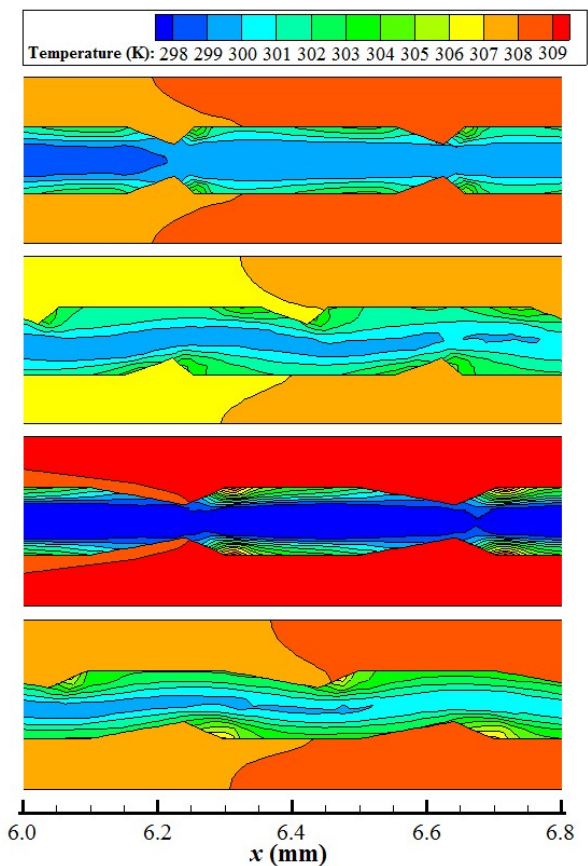

(b) 
Fig. 4

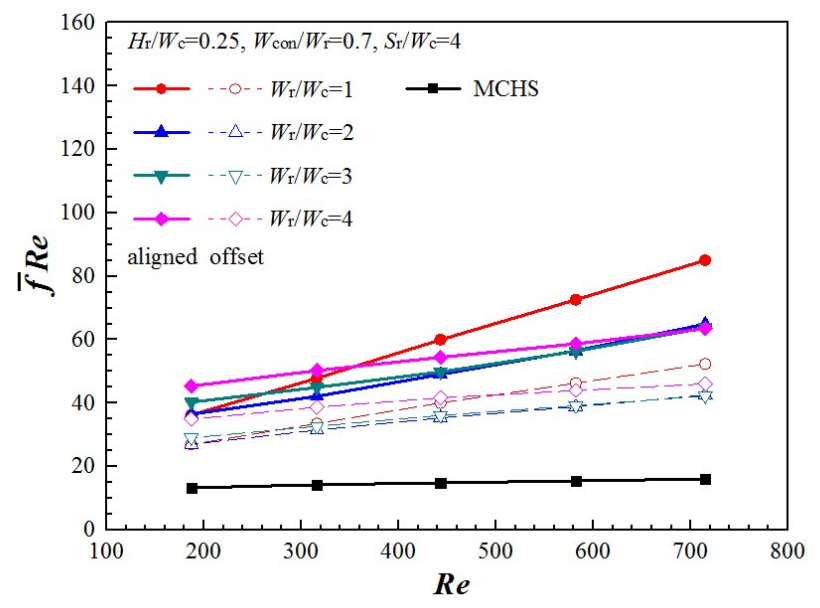

(a)

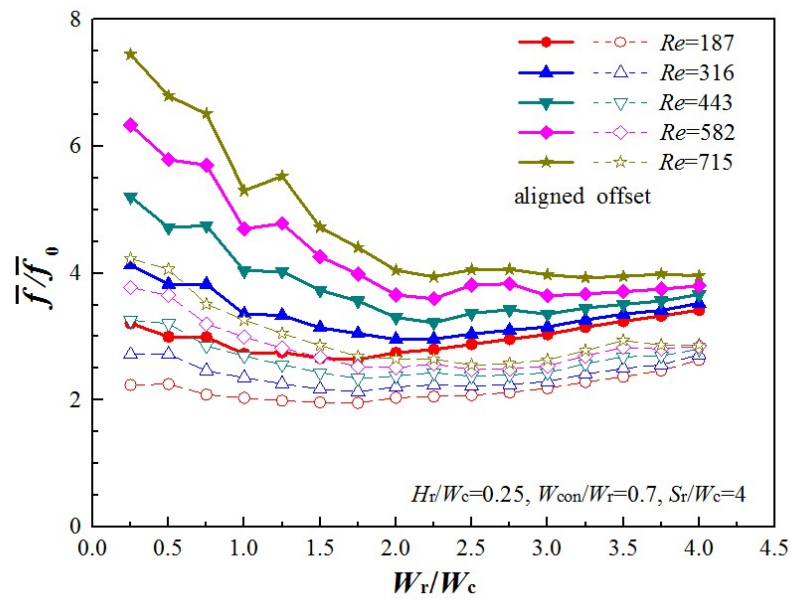

(b) 
Fig. 5

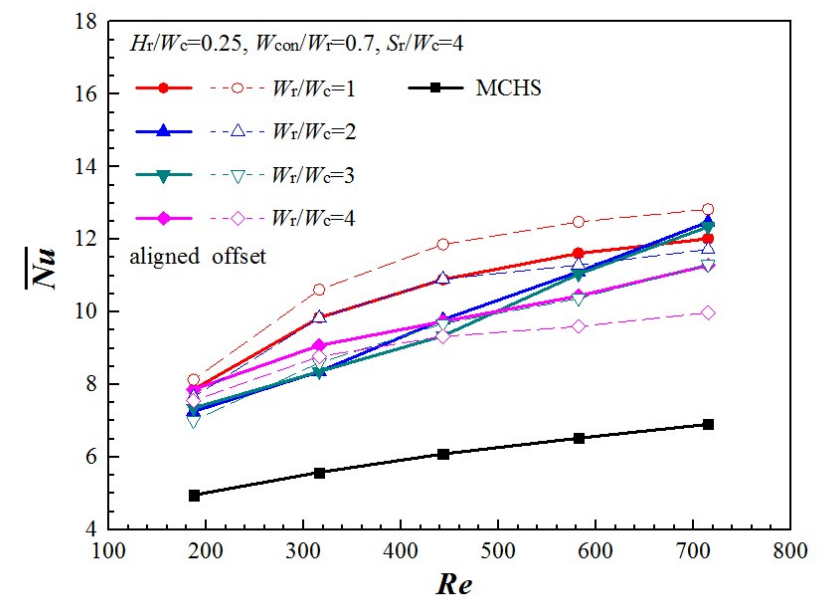

(a)

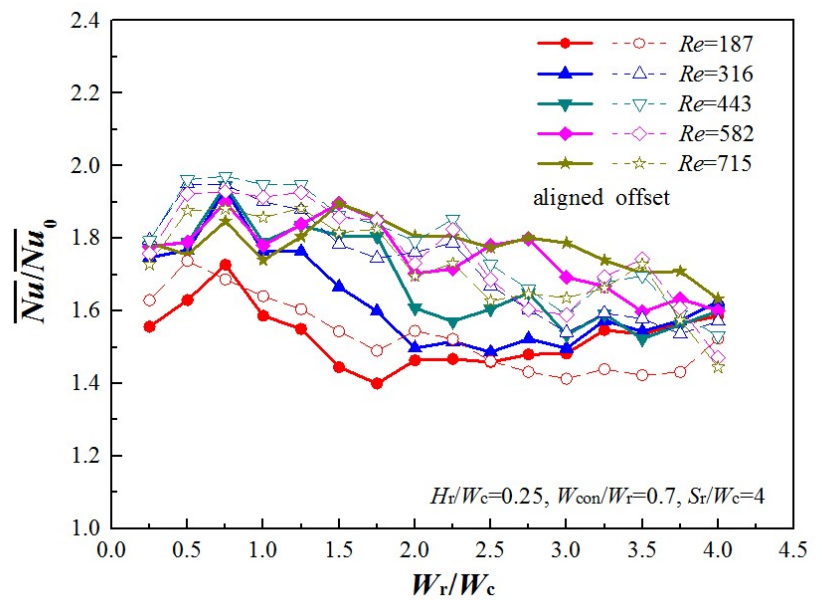

(b) 
Fig. 6

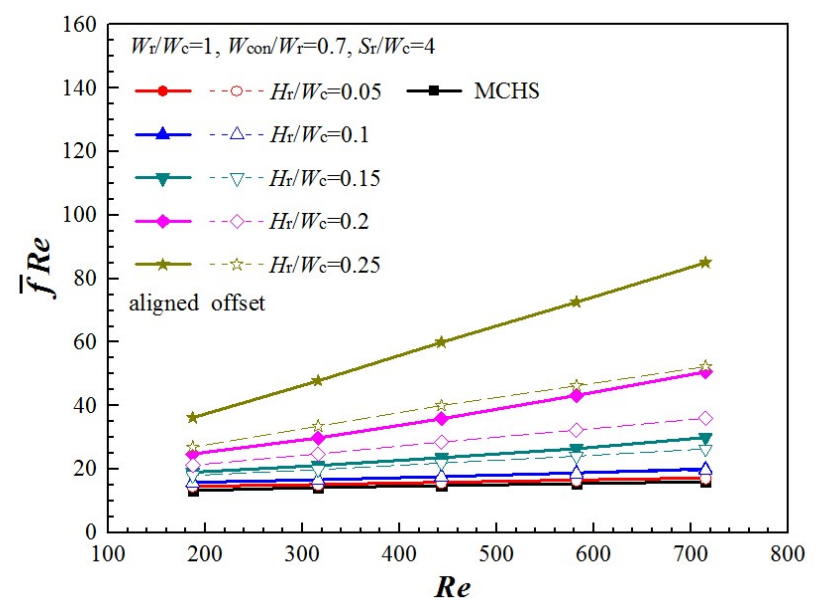

(a)

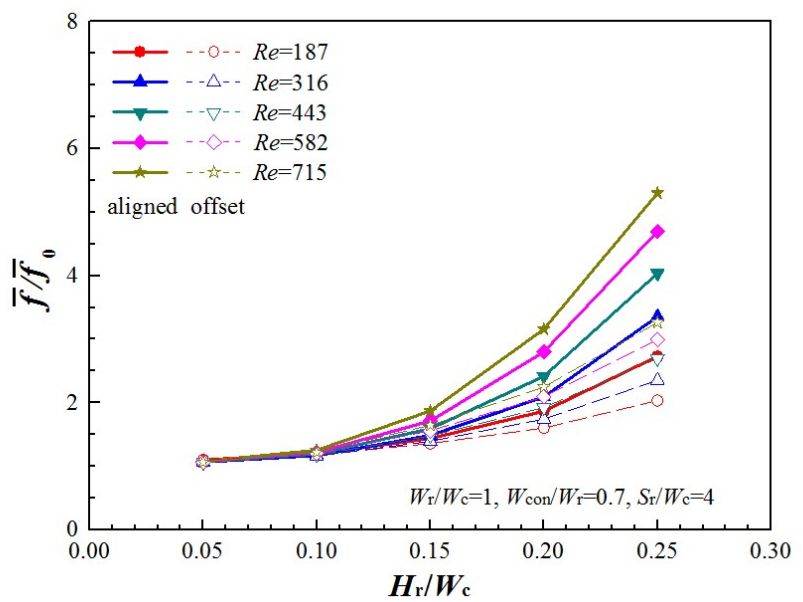

(b) 
Fig. 7

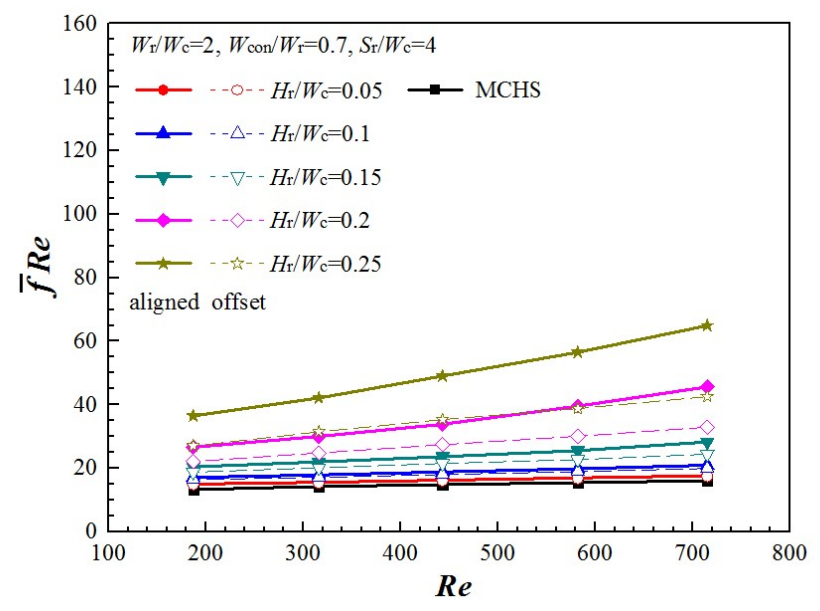

(a)

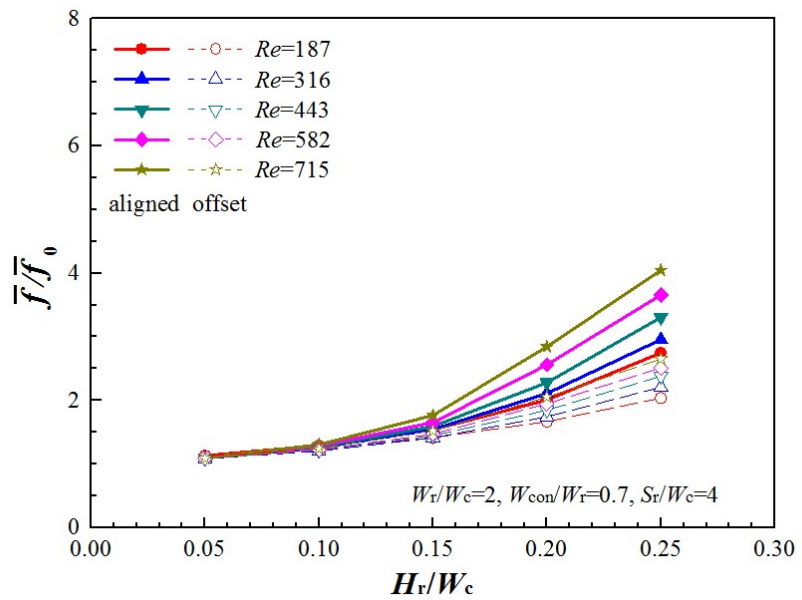

(b) 
Fig. 8

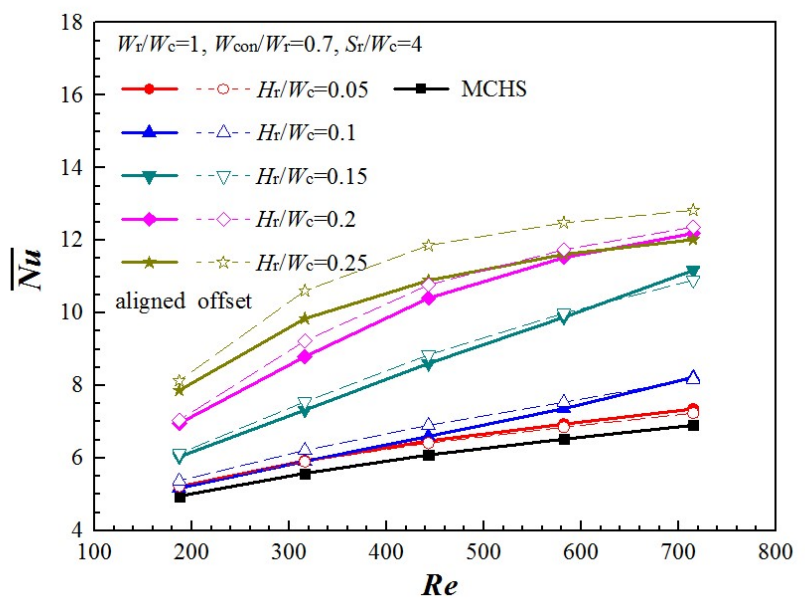

(a)

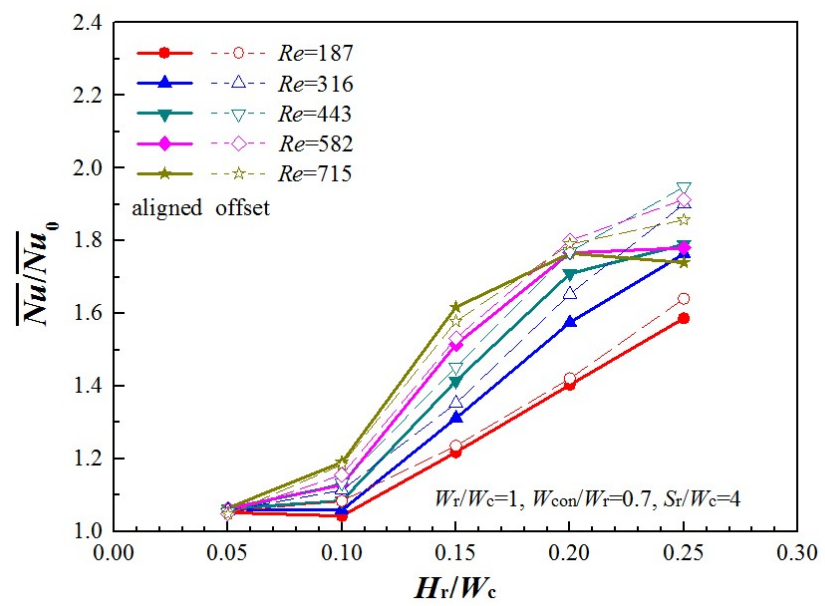

(b) 
Fig. 9

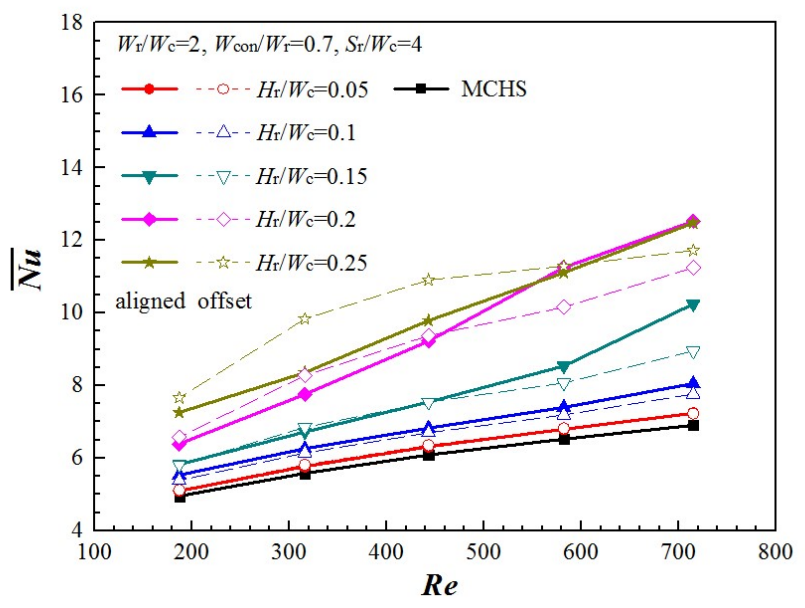

(a)

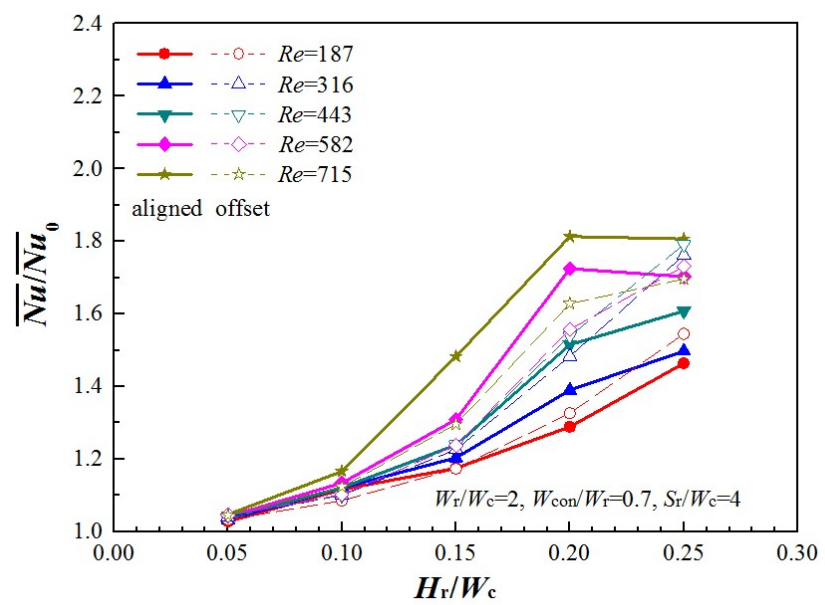

(b) 
Fig. 10

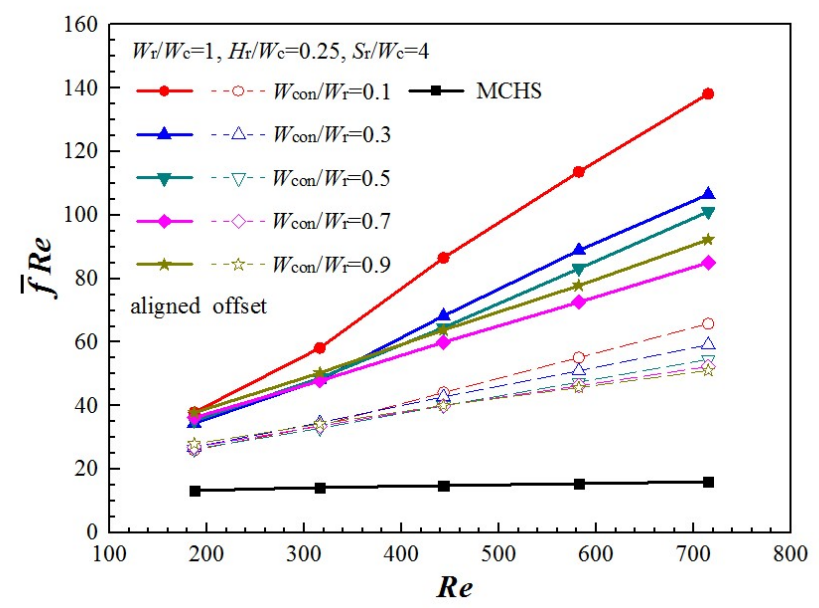

(a)

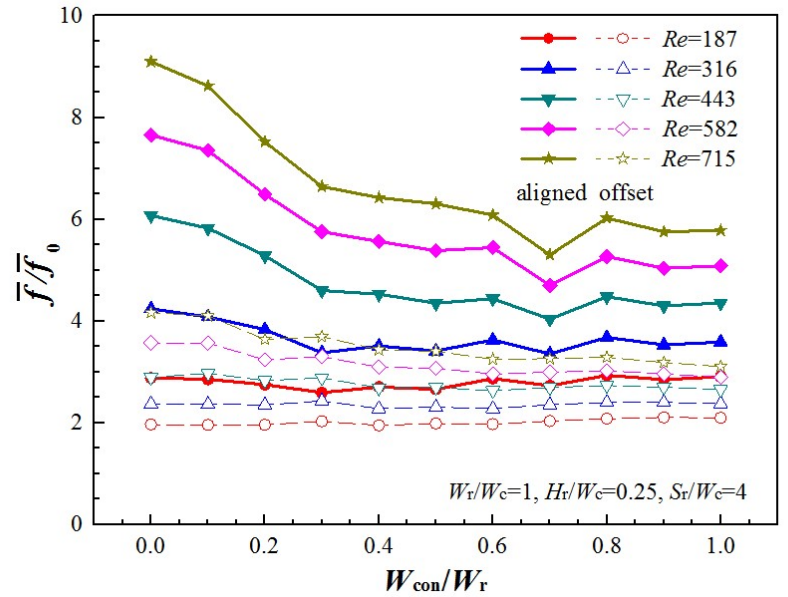

(b) 
Fig. 11

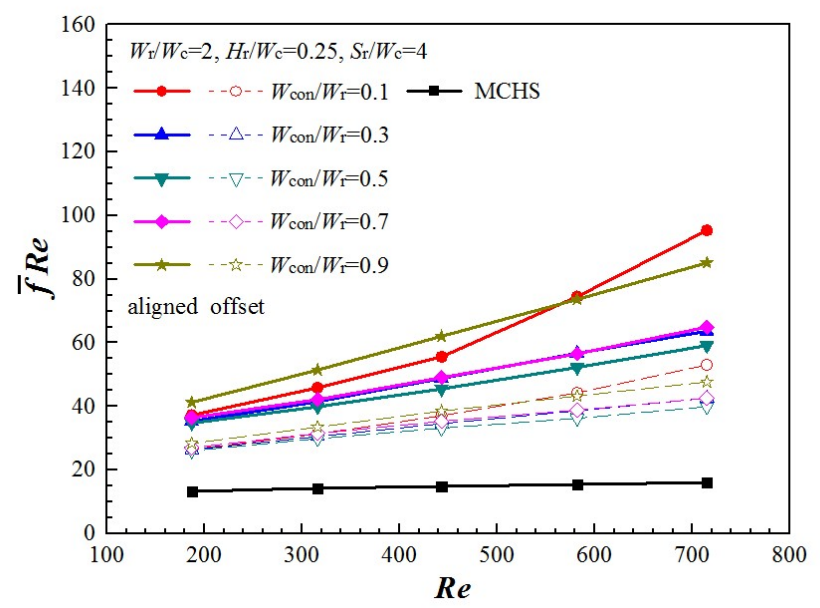

(a)

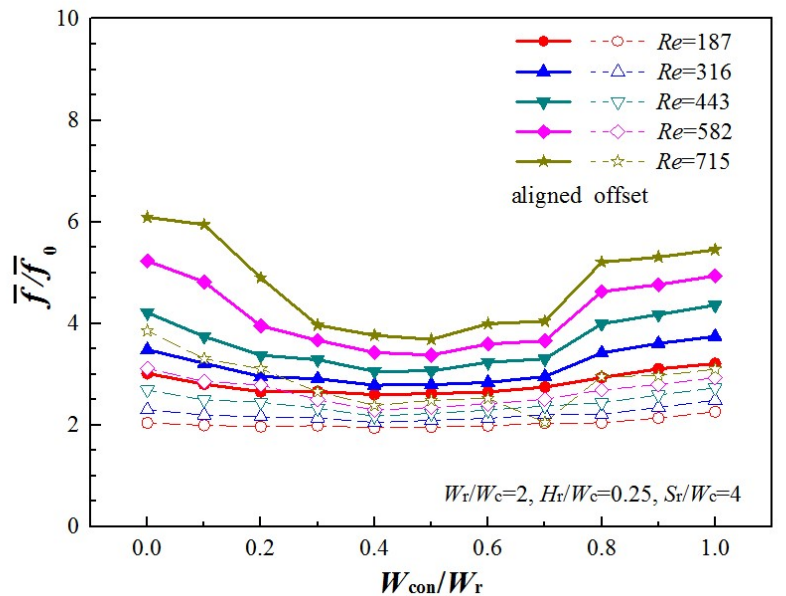

(b) 
Fig. 12

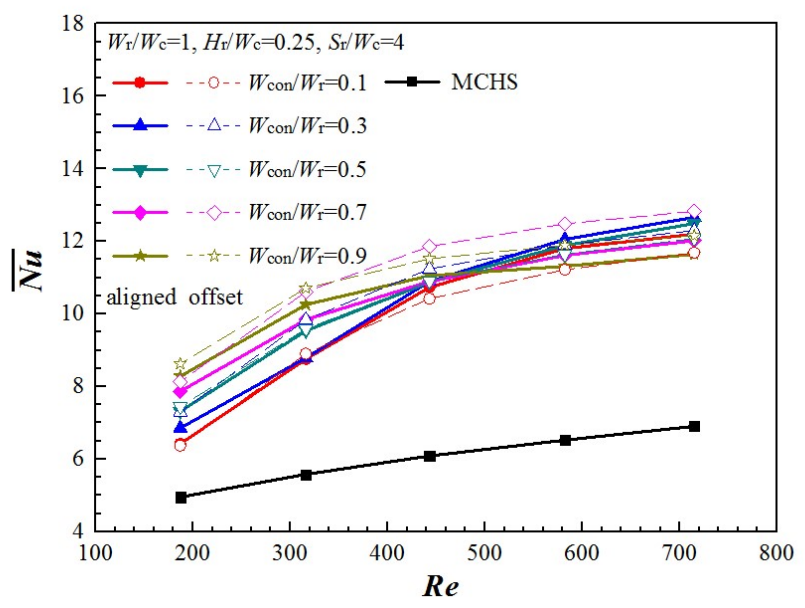

(a)

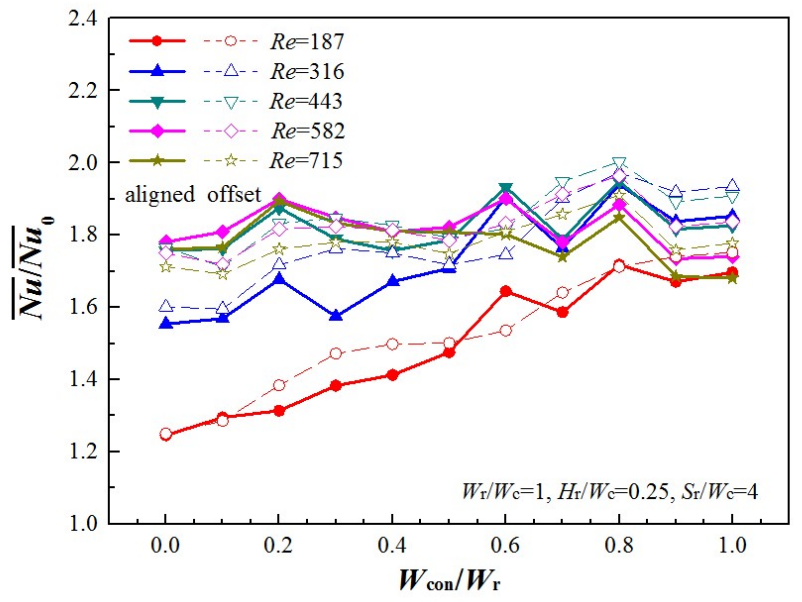

(b) 
Fig. 13

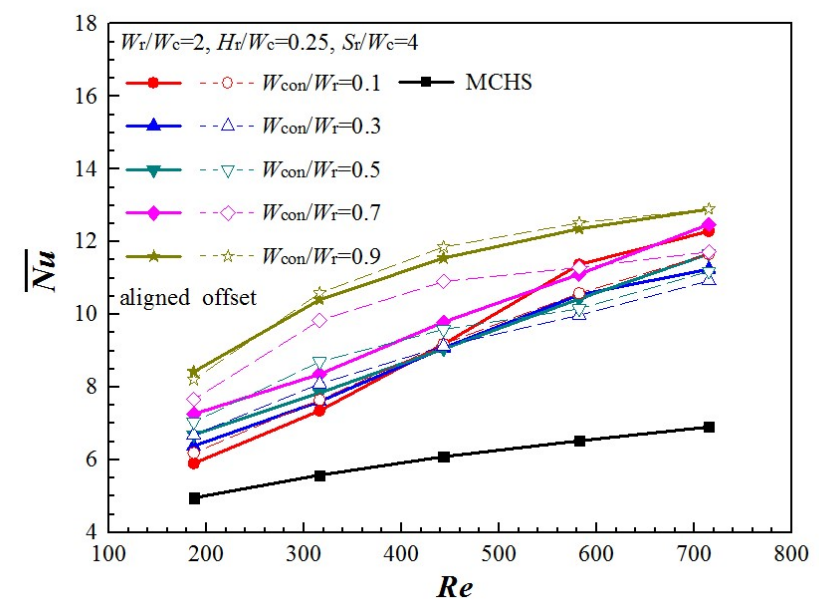

(a)

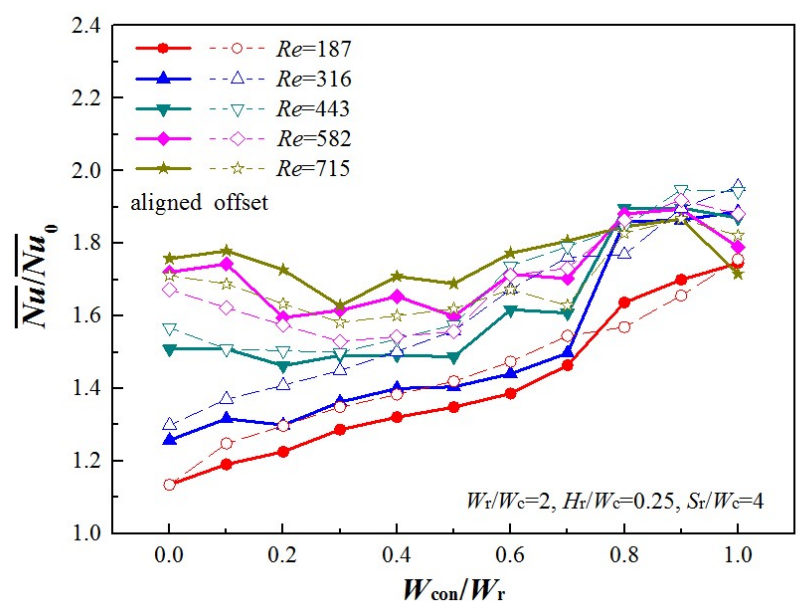

(b) 
Fig. 14

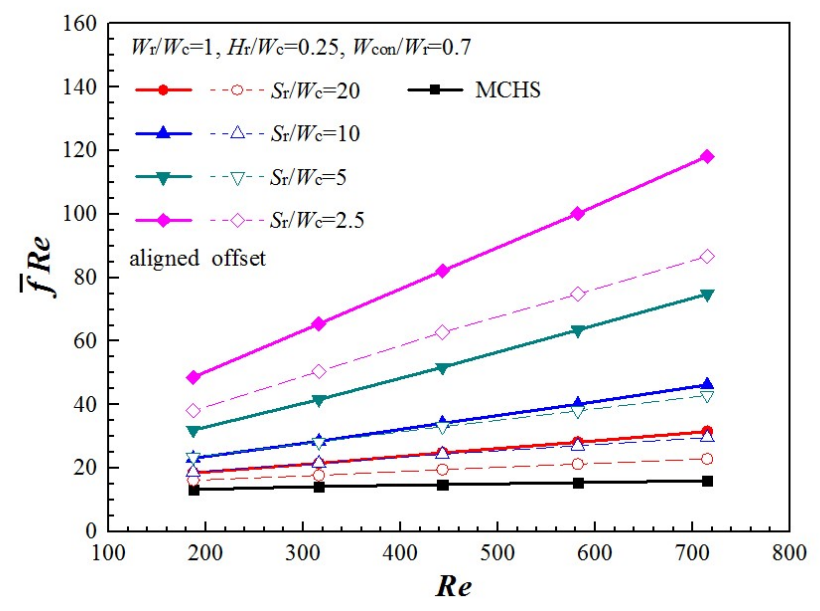

(a)

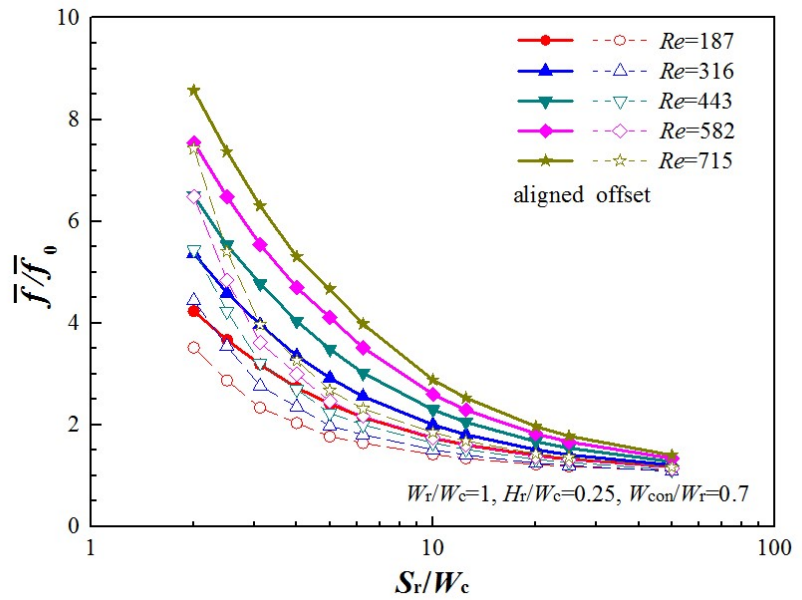

(b) 
Fig. 15

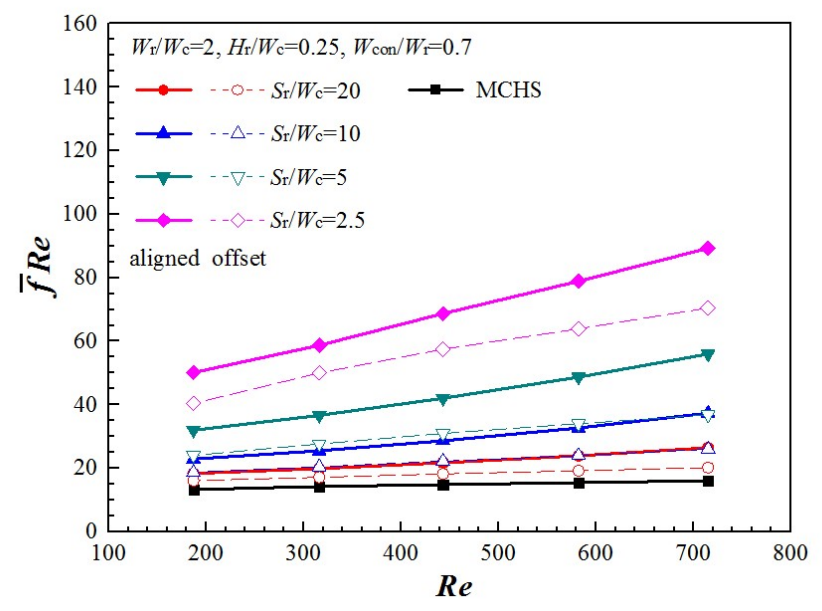

(a)

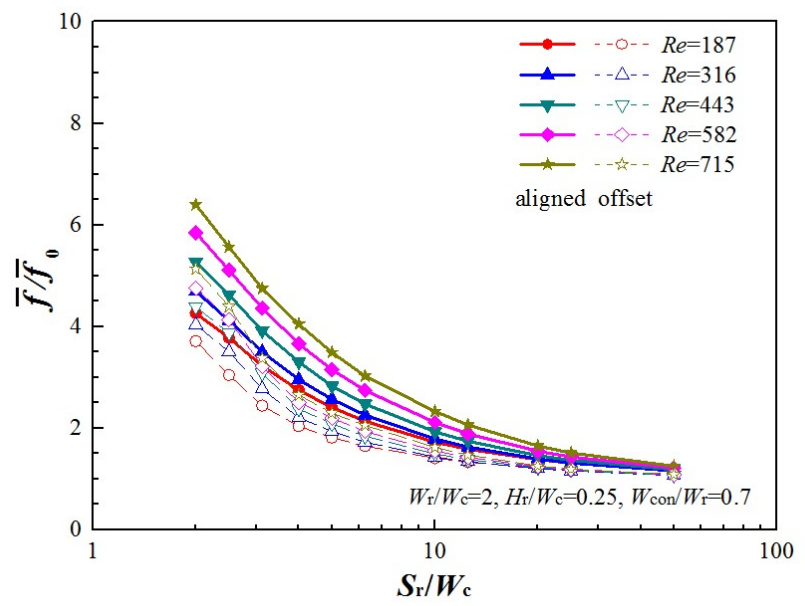

(b) 
Fig. 16

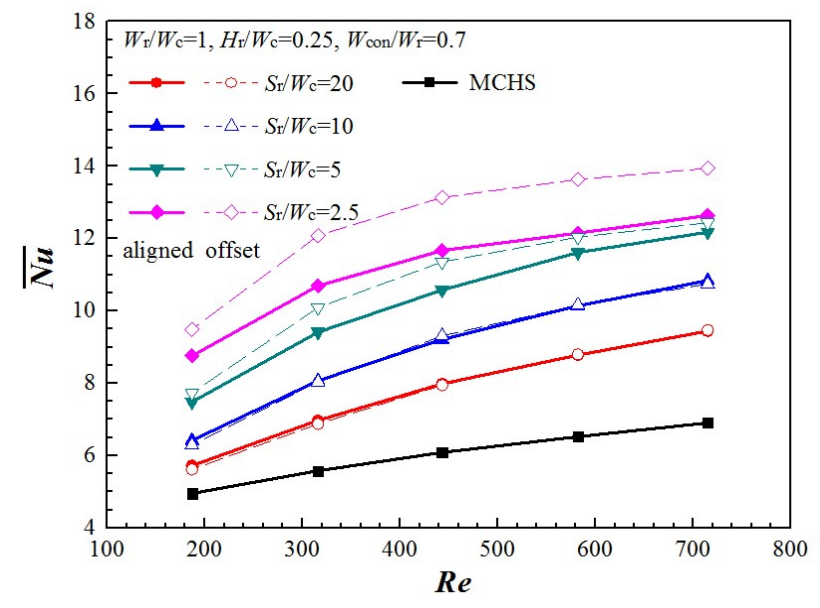

(a)

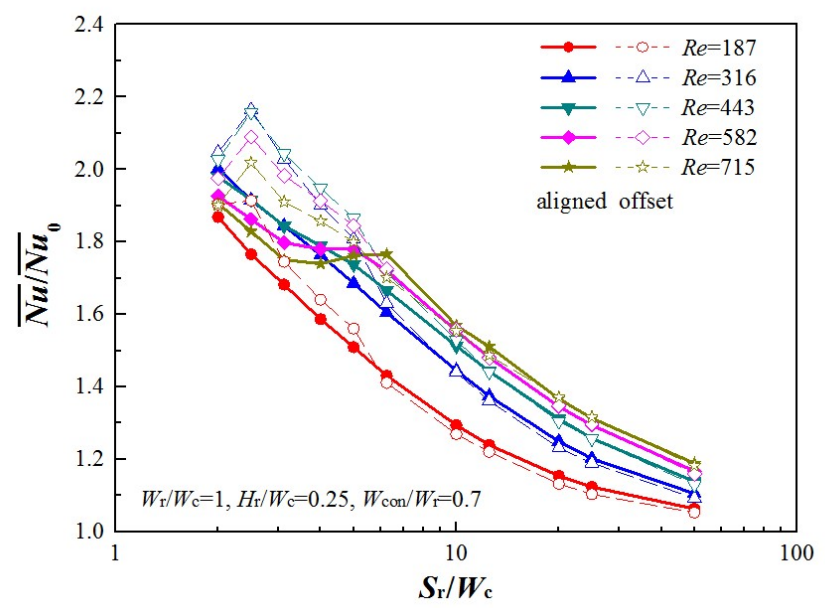

(b) 
Fig. 17

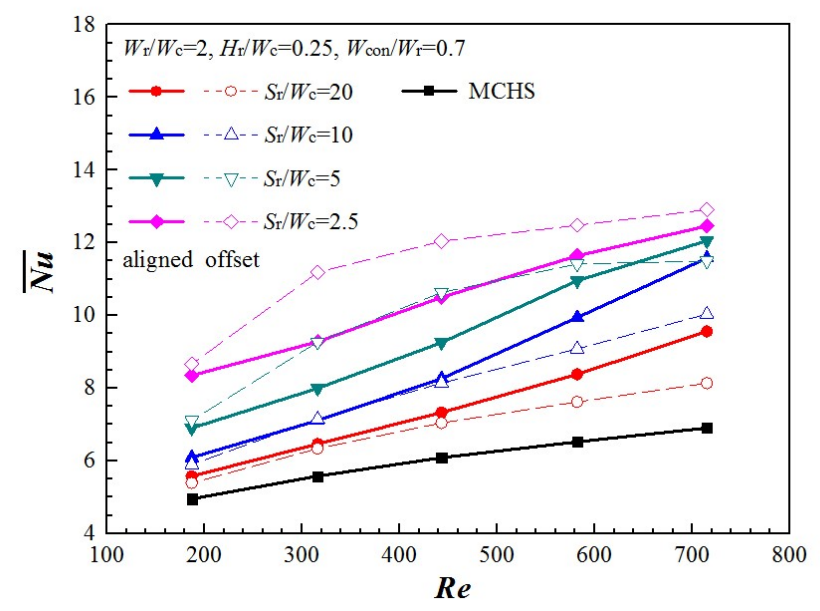

(a)

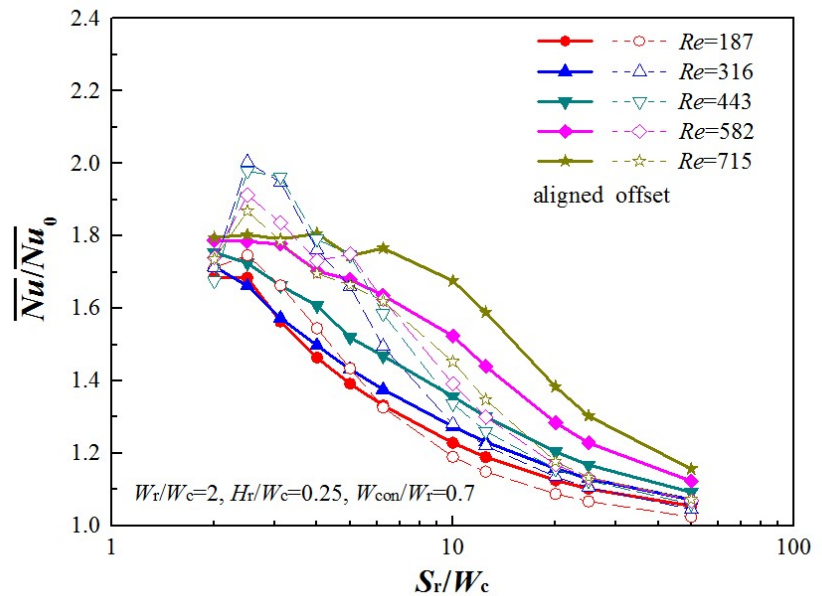

(b) 
Fig. 18

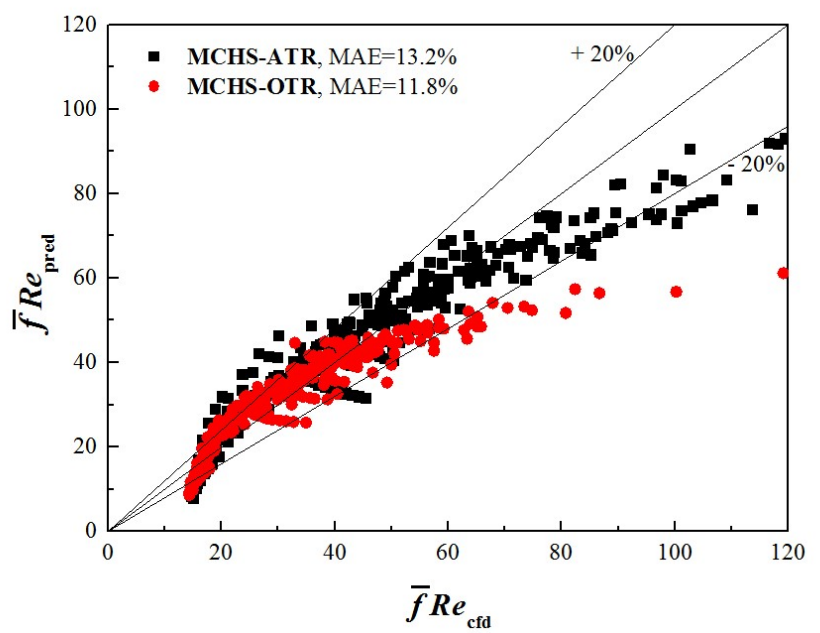

(a)

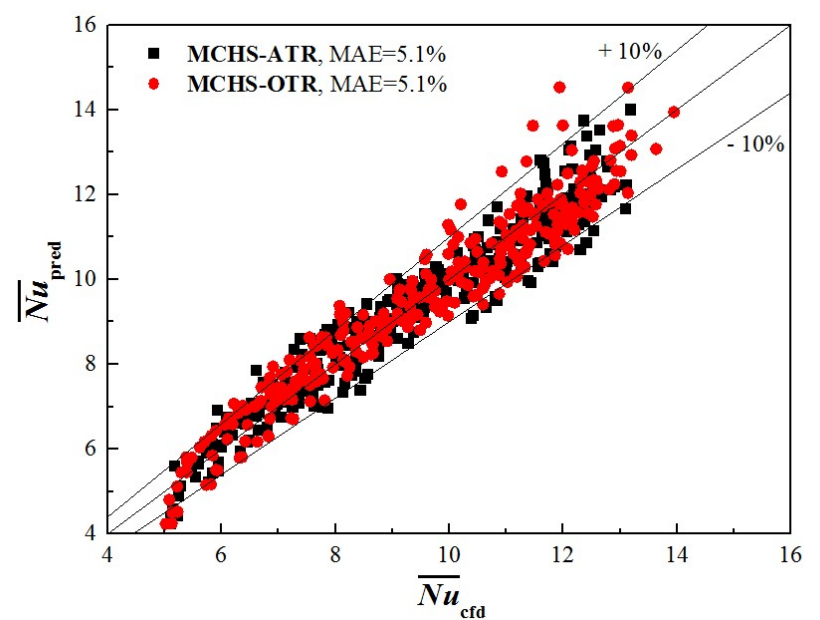

(b) 